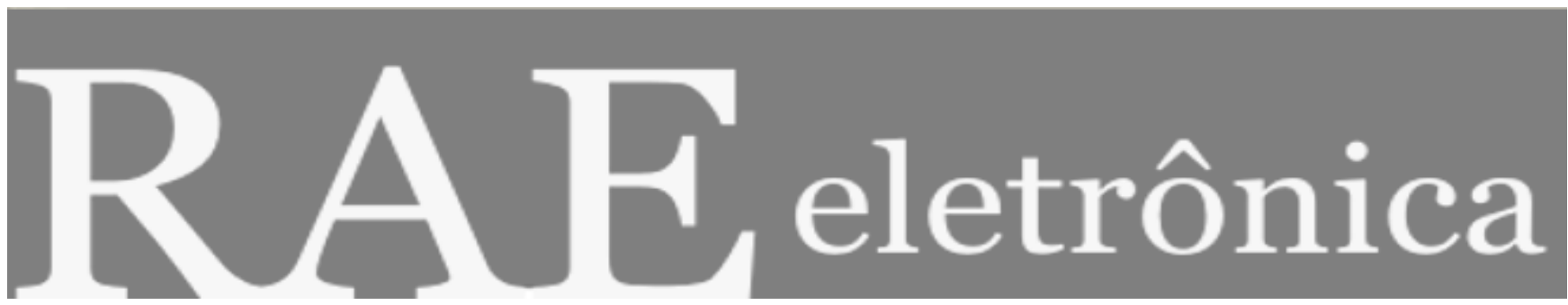

\title{
DA OBSERVAÇÃO À DECISÃO: MÉTODOS DE PESQUISA E DE ANÁLISE QUANTITATIVA E QUALITATIVA DE DADOS
}

Por

Henrique Freitas

Jean Moscarola

RAE-eletrônica, Volume 1, Número 1, jan-jun/2002.

http://www.rae.com.br/eletronica/index.cfm?FuseAction=Artigo\&ID=1159\&Secao=INFORMAÇÃO\&Volume=1\&Numero $=1 \& A n o=2002$

CCopyright, 2002, RAE-eletrônica. Todos os direitos, inclusive de tradução, são reservados. É permitido citar parte de artigos sem autorização prévia desde que seja identificada a fonte. A reprodução total de artigos é proibida. Os artigos só devem ser usados para uso pessoal e nãocomercial. Em caso de dúvidas, consulte a redação: redacao@rae.com.br.

A RAE-eletrônica é a revista on-line da FGV-EAESP, totalmente aberta e criada com o objetivo de agilizar a veiculação de trabalhos inéditos. Lançada em janeiro de 2002, com perfil acadêmico, é dedicada a professores, pesquisadores e estudantes. Para mais informações consulte o site www.rae.com.br/eletronica.

RAE-eletrônica

ISSN 1676-5648

(C)2002 Editora: Fundação Getulio Vargas - Escola de Administração

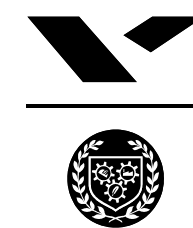

F U N D A C C Ã O GETULIO VARGAS

de Empresas de São Paulo. 


\title{
DA OBSERVAÇÃO À DECISÃO: MÉTODOS DE PESQUISA E DE ANÁlISE QUANTITATIVA E QUALITATIVA DE DADOS ${ }^{1}$
}

\section{Henrique Freitas $^{2}$}

Mestre em administração pelo PPGA/EA/UFRGS . Doutor em gestão pela ESA/UPMF (França)

E-mail: hf@ea.ufrgs.br

Endereço: EA/UFRGS, Rua Peru, 211. Canoas, RS. 92420-300.

Interesses de pesquisa: Sistemas de informação, apoio à decisão, comércio eletrônico, sistemas para análise de dados.

\section{Jean Moscarola}

Doutor em gestão pela Université de Paris. Diretor de pesquisa (Irege, Annecy, França).

E-mail: moscarola@,univ-savoie.fr

Endereço: Rua Peru, 211. Canoas, RS, 92420-300

Interesses de pesquisa: Novas tecnologias de informação e de comunicação, sistemas para análise de dados.

\section{RESUMO}

A atividade de pesquisa hoje deixa de pertencer somente aos centros acadêmicos e instituições especializadas para se incorporar no dia-a-dia das empresas e demais organizações. Frente a um ambiente de negócios amplo e turbulento, a pesquisa passa a representar um recurso de grande poder para se coletar, analisar e extrair informações valiosas de dados, tanto externos como internos às organizações. Este artigo visa fornecer algumas noções básicas sobre métodos e técnicas de pesquisa e de análise quantitativa e qualitativa de dados. Através de alguns preceitos básicos sobre a atividade de pesquisa, e também através de diversos exemplos práticos de enquêtes que lançam mão desse tipo de análise), verifica-se o seu potencial de uso para a realização de investigações que podem trazer importantes subsídios para processos de tomada de decisão nas organizações, também servindo aos pesquisadores nas investigações de maior rigor científico.

\begin{abstract}
We can find more and more the research activity not only inside the academical world, but especially inside the organizations. Facing a turbulent business environment, research is becoming a essential resource in order to allow managers to collect and provide the internal and external information for decision-making. This paper aims to describe some basical notions concerning research methodology and quantitative and qualitative data analysis, developing some examples.
\end{abstract}

\footnotetext{
1 Este artigo teve sua origem na conferência de mesmo título proferida pelo professor Jean Moscarola em março de 1996, no auditório da FIERGS, em Porto Alegre - RS (Brasil), com a participação de Henrique Freitas. Os autores agradecem às então bolsistas de Iniciação Científica CNPq Ionara Rech, Ângela Werner e Luciana Piatnicki, que tiveram colaboração fundamental na edição do texto original no qual se baseou este artigo. Amarolinda Zanela Saccol, à época mestranda do PPGA/EA/UFRGS, hoje Professora da Unisinos, cooperou na edição e revisão técnica do documento. Mirian Oliveira, Professora da PUCRS e Pesquisadora CNPq revisou o documento para publicação em 2001.

2 Em continuidade à agenda de pesquisas definida por FREITAS e BECKER (1995), este trabalho foi preparado pela equipe do GESID (Grupo de Estudos em Sistemas de Informação e Apoio à Decisão, PPGA, Escola de Administração da UFRGS, Brasil), num esforço coordenado pelo Professor Henrique Freitas, no período em que se encontrava como Pós-doutorando e professor visitante na University of Baltimore (USA) e na Université de Savoie (França), e contando com o apoio de agências de fomento à pesquisa: CNPq, Fapergs, Propesp/UFRGS e programa CAPES/COFECUB.
} 
PALAVRAS-CHAVE

Henrique Freitas - Jean Moscarola

Método de pesquisa, análise quantitativa e qualitativa, informação, decisão.

\section{KEYWORDS}

Research method, quantitative and qualitative data analysis, information, decision. 


\section{INTRODUÇÃO}

Este trabalho tem por objetivo apresentar métodos de pesquisa e de análise quantitativa e qualitativa de dados, buscando destacar a sua importância como recursos auxiliares no sistema de informação que apóia a tomada de decisão no dia-a-dia tanto do pesquisador como do homem de negócios.

Atualmente convive-se permanentemente com um grande volume de dados disponibilizados através das tecnologias de informação. Verifica-se que tais dados necessitam cada vez mais de um tratamento prático e de bom senso que os transformem em INFORMAÇÃO pertinente (DAVIS e OLSON, 1989; FREITAS, BECKER e outros, 1997). A análise criteriosa de dados tanto internos como externos a uma organização (informações normalmente públicas) torna-se cada vez mais necessária (FREITAS e LESCA, 1992), dada a escassez de tempo e a cobrança por agilidade e flexibilidade imposta pelo mercado - um mercado que, sabe-se bem, ganha a cada momento possibilidades maiores, através da abertura que hoje ocorre em quase todos os setores (PORTER, 1992). Já não existe mais o problema de acesso aos dados (vide a Internet, que representa por si só uma fonte inesgotável): o grande desafio que hoje confrontamos é a tomada do conhecimento através dos dados.

Por outro lado, a busca por informações consistentes e válidas não mais pode deter-se aos dados estruturados, puramente quantitativos, tal qual os imaginamos - na forma de clássicas planilhas, relatórios volumosos, números, percentuais e gráficos - cada vez mais precisamos ir aos dados de natureza qualitativa, como textos, discursos, entrevistas, trechos de livros, reportagens, etc. Dados que envolvem elementos que muitas vezes desafiam a astúcia do pesquisador ou do homem de negócios, pois escondem em suas entrelinhas posicionamentos, opiniões, perfis, que exigem uma leitura atenta e ferramentas (tal qual a lupa de um detetive) que possibilitem chegar com maior rapidez (condição de sobrevivência) às informações realmente pertinentes (POZZEBON e FREITAS, 1996; LESCA, FREITAS e CUNHA, 1996).

A informação serve à tomada de decisão, logo a necessidade de decidir com maior precisão, por conseguinte, é obviamente justificada pela necessidade que temos em agir, dentro das organizações e no campo da pesquisa. Com informações consistentes, chega-se não só às decisões mais acertadas, mas também a uma 'venda' mais eficaz dessas decisões perante o nosso 'público-alvo' (FREITAS, BALLAZ e TRAHAND, 1993; FREITAS, BRONGER e CALDIERARO, 1994 e 1995). Muitas vezes precisa-se, no dia-a-dia, justificar de maneira mais formal decisões que se norteiam principalmente pelo bom senso, isto melhor convencendo àqueles que preferem dados analisados e apresentados com maior estruturação.

Frente a esta conjuntura, e ao volume de informações que precisamos 'esculpir', estruturar o desestruturado e desestruturar o que parece tão preciso é um exercício que se impõe, pois é preciso cada vez mais saber 'ler' nos dados o que o mercado, os clientes, os concorrentes e outros atores importantes do ambiente interno e externo estão realmente dizendo, ainda que o digam de forma mais indireta ${ }^{3}$.

3 As pesquisas realizadas pelo Professor Jean Moscarola, na França, e pelo Professor Henrique Freitas, no Brasil, buscam definir características, funcionalidades, arquitetura de sistemas de informações que venham a facilitar a vida do gerente, executivo, decisor, analista, pesquisador, ou mesmo que venham a propiciar melhores condições de proatividade a estes (este projeto teve a co-participação de duas então mestrandas, Marlei Pozzebon e Maira Petrini, Gesid-PPGA, Escola de Administração da UFRGS). 
Com o objetivo de demonstrar métodos que, utilizados com o auxílio de uma ferramenta estatística eficaz, possam auxiliar o pesquisador, o homem de negócios, os DECISORES, enfim, na busca por conhecimento, serão apresentadas algumas técnicas de pesquisa e de análise quantitativa e qualitativa de dados, técnicas estas que serão ilustradas através de pequenos casos onde apresentam-se pesquisas realizadas no meio empresarial e acadêmico, refletindo-se, ao final de cada caso, sobre as conclusões e informações extraídas em cada um dos exemplos e diretamente utilizadas na prática.

\section{O HOMEM DE ESTUDOS VS. O HOMEM DE AÇÃO: alguns pressupostos básicos sobre a atividade de pesquisa}

A Figura 1 evidencia uma crença sem a qual todo o propósito deste artigo não teria validade:

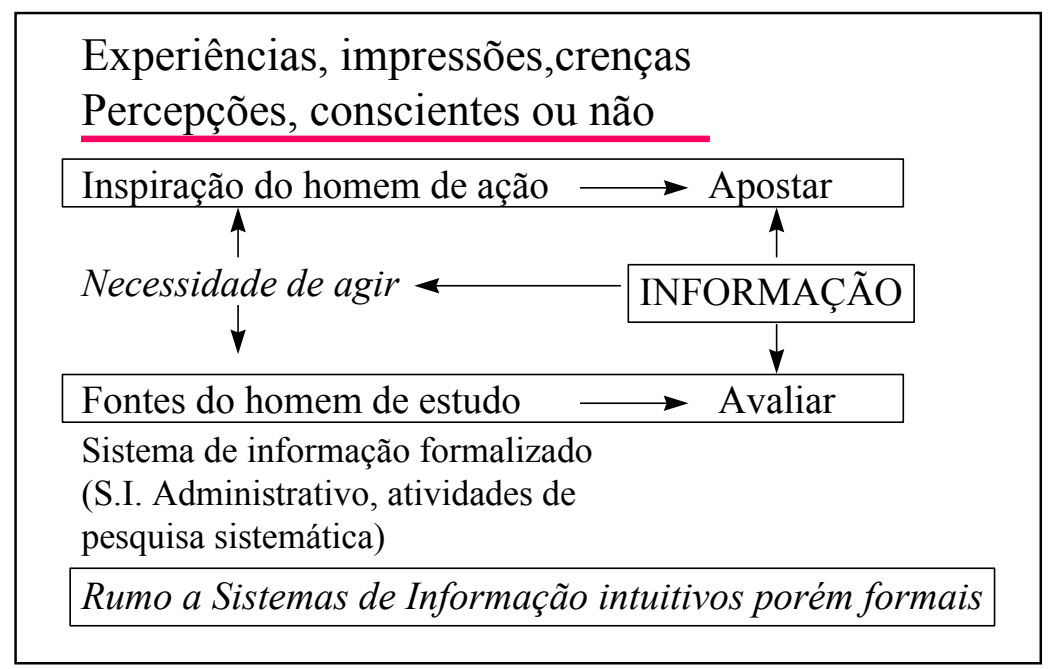

Figura 1 - O homem de ação x o homem de estudos

Considerando a necessidade de agir, percebe-se que as pessoas podem responder a esta necessidade de duas formas: a maneira que está escrita na parte superior da Figura 1 - apostar - é uma resposta impulsiva. Responde-se à ação com ação. Outra maneira, demonstrada na parte inferior da figura, consiste em - antes de agir - consultar fontes, perceber desvios entre as relações; desvios reflexivos que levam a examinar as informações formais que se tem à disposição no sistema de informações administrativas: livros, atividades de pesquisa desenvolvidas de maneira sistemática (CALDIERARO, FREITAS, PETRINI e POZZEBON, 1998).

A crença que se possui, a princípio, é a de que o desvio pela reflexão, que leva à decisão, irá permitir uma ação melhor do que a simples reação estimulada pelas sensações que se sente no mundo que nos cerca. Diz-se que se trata, neste caso, de uma crença, pois não se tem total convicção de que a simples ação oposta à decisão não é suficiente em muitos casos. A convicção de muitos pesquisadores é de que essa via, que passa pelo desvio da reflexão, é muito útil, desde que não se esqueça da

Como tal projeto pressupõe que se conheça, e bem, os decisores, uma outra pesquisa ocorreu em paralelo, desenhando o perfil dos tomadores de decisão na França, no Brasil e nos Estados Unidos, coordenada pelos dois professores já mencionados, e pelos Professores João Luiz Becker (GesidPPGA/EA/UFRGS) e Milton Jenkins (ISRC, Merrick School of Business, University of Baltimore, USA), e com a co-participação de duas outras também então mestrandas, Amarolinda Costa Zanela e Marie A. Macadar (Gesid-PPGA/EA/UFRGS). 
necessidade de reagir rapidamente. Esta é, portanto, uma abordagem integrada a ser defendida, a qual consiste em utilizar de uma maneira razoável a reflexão, sem no entanto jamais esquecer da necessidade da ação. Em nossas atividades de estudo, de pesquisa, somos cientistas. Mas existem outros tipos de pesquisadores, como por exemplo, os detetives, com os quais se faz a seguir uma analogia, ilustrada na Figura 2.

Primeiramente, cita-se o personagem de Ágatha Christie, Hercule Poirot, cuja característica é a resolução de enigmas que se desenvolvem em locais fechados, em uma unidade de tempo bastante reduzida. Ele utiliza um processo muito característico, que consiste em escutar e formular algumas perguntas em um local, comodamente instalado, numa biblioteca da casa onde o crime fora cometido. É através da reflexão, ao exercer um raciocínio procurando os motivos, as possibilidades de ação, de uma maneira totalmente teórica, que Poirot descobre quem é o assassino, pois ele reúne, com lógica, informações sobre como se conseguiu cometer o ato que se quer condenar. A abordagem de Hercule Poirot é teórica, na medida em que ele utiliza apenas a lógica e o conhecimento geral que possui a respeito dos homens, das suas motivações e de seus comportamentos. Ele tem uma mente privilegiada, sabendo raciocinar e não utilizando outros meios que não a sua inteligência. Em muitas situações de decisão, raciocinar como Hercule Poirot é realmente um bom método. Além disso, este método tem a vantagem de custar pouco. Freqüentemente, alguns cálculos feitos no canto de uma mesa dizem mais do que dispendiosas pesquisas.

O segundo detetive é um personagem francês: Maigret. Os seus romances nos transportam para um universo bastante diferente daquele de Poirot. Maigret é um personagem que viaja. Ele não se encontra no local do crime. Ele vai até os locais onde a história se desenrola. Ele se desloca, se instala em um hotel médio da cidade e empreende no bar do mesmo uma discussão, a princípio sem objetivos, com as pessoas do lugar. Aparentemente, ele não faz pesquisa. Profundamente, ele procura entender onde está e como são as pessoas que estão ao seu redor. Por isso, ele pode ser comparado a um etnólogo: aquele que vai viver junto à sociedade que está estudando para entendê-la. A informação vem para Maigret, mais do que Maigret vai para a informação. A primeira qualidade é que ele está disponível, curioso e sensível. Ele utiliza toda a sua perspicácia para chegar ao conhecimento. Poirot é o pólen, a intuição. Custa um pouco mais chamar Maigret, pois é preciso pagar a viagem e a estadia.

$\mathrm{O}$ terceiro personagem é Sherlock Holmes, freqüentemente representado em uma postura estranha, ajoelhado, observando um detalhe, munido com uma lente de aumento. É essa lente que faz a distinção de Holmes dos outros detetives. Essa lente de aumento, essa medida lhe permite entrar no detalhe insignificante, fazer com que apareça, por exemplo, o brilho encontrado sob a sola de um dos suspeitos, o que é na verdade uma palha, e que esta palha é exatamente da mesma textura que a do chapéu da vítima. Ao ampliar o detalhe insignificante, graças à lente de aumento, Holmes obtém a prova que irá identificar o assassino. É um terceiro método. 


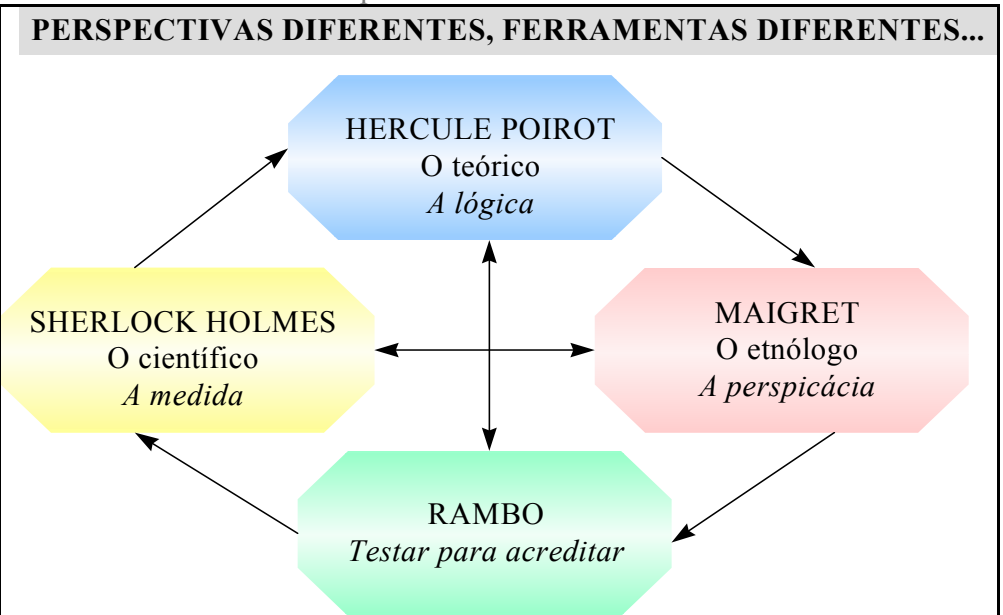

Figura 2 - Diferentes tipos de pesquisadores

Poirot só tem a inteligência. Maigret viaja, se instala e precisa de tempo. Sherlock Holmes é um personagem que tem aparelhos e utiliza instrumentos. O teórico, o etnólogo e, pode-se dizer de Holmes, o científico. Científico pois, pela lente de aumento, beneficia-se medindo e conferindo pelo 'mistério' da ciência. Porém, é preciso saber olhar através de uma lente de aumento.

Os métodos que serão abordados neste estudo são semelhantes aos de Holmes - a medida. A lente de aumento utilizada é um questionário, a estatística, o computador. Mas, antes de se tratar a respeito destes instrumentos, é muito importante ressaltar que Holmes, sem a inteligência e a lógica de Poirot e sem a perspicácia de Maigret, é um homem bastante desprovido. Se ele tiver de aumentar a sola de todos os habitantes da aldeia com a lente, irá perder as forças. A lente só é útil quando for orientada por um braço inteligente e sensível. A lógica irá permitir limitar o conjunto dos suspeitos e a intuição permitirá uma maior velocidade para se chegar ao assassino. Por conseguinte, o fato de que se dispor de lentes de aumento nunca deve fazer esquecer que raciocinar e sentir são dois requisitos fundamentais.

Existe, por fim, um quarto personagem. Trata-se de Rambo (sim, ele mesmo!). Ele é muito diferente dos três intelectuais. Rambo também é um personagem com instrumentos, porém de outros tipos. Tem como característica formular poucas perguntas. Quando vê o campo inimigo, ele se pergunta se há alguém no local. Imediatamente, ele utilizará a granada ou a bazuca e se houver gritos é porque alguém estava lá. E, se, infelizmente, ele encontra a placa de quem era o inimigo, acredita que venceu. Rambo age por tentativa, antes de refletir. É a ação que vai lhe trazer informações. Rambo pode parecer cômico, mas não se pode esquecer que às vezes é mais interessante agir do que refletir em demasia.

A estratégia e o tipo de pesquisa a ser adotada irá depender da situação que se apresenta, dos objetivos que se tem, das exigências de tempo e recursos. É nessa ponderação que deve prevalecer o bom senso do pesquisador. É importante considerar (ainda que este seja um exercício um tanto complexo) qual o valor da informação que se deseja obter, bem como o grau de precisão desejado.

Tendo em vista estes preceitos básicos, na Seção 3 são tratadas, de forma objetiva e sucinta, as principais etapas que envolvem o planejamento e implementação de uma investigação. Neste trabalho, o tipo de pesquisa a ser tratada são enquêtes, investigações de natureza quantitativa e qualitativa, apresentando-se na seqüência diversos casos de aplicação prática desse tipo de método. 


\section{3 - O PLANEJAMENTO DE UMA INVESTIGAÇÃO}

Ao iniciar uma investigação, um ponto crucial - e que na maioria das vezes irá determinar o seu sucesso - é definir, da maneira mais precisa possível, os objetivos que se pretende alcançar, as questões que realmente se deseja responder e esclarecer ${ }^{4}$.

\section{1 - O ponto de partida: a formulação do problema}

A primeira etapa do planejamento de uma investigação consiste em formular muito bem o problema, as questões que se deseja pesquisar: qual o objeto da investigação? Trata-se de determinar o bom nível do preço de um produto? Ou trata-se de saber se um produto atende às necessidades do consumidor? Nesta etapa é recomendável ter consciência da pergunta a ser formulada, e ao mesmo tempo refletir sobre os meios para se obter a resposta. Contudo, deve-se considerar o tempo do qual se dispõe para planejar e implementar a pesquisa e os meios disponíveis para o engajamento num processo mais ou menos dispendioso.

Se existem os meios, pode-se talvez ter pouco tempo e será necessário utilizar a inteligência com certa rapidez. Com um pouco mais de tempo, pode ser necessário ir a campo apenas com a intuição, então observar e, por fim, se deseja-se uma maior precisão e conhecimento a respeito dos fatos (e isso custa mais e toma mais tempo), serão então utilizados os métodos de observação tratados neste estudo.

Neste caso, a primeira fase consiste em fazer pesquisas prévias como Maigret, como Poirot, indo ao 'local do crime', nas bibliotecas para pesquisas, em livros e revistas, na Internet e em outras fontes de informações que possam fornecer melhores elementos para a investigação da pergunta formulada. Um balanço dos conhecimentos já existentes no campo de pesquisa que se deseja ingressar é fundamental, pois direciona e torna mais objetiva e delineada a investigação, poupando-se tempo em reinvenções. O passo a seguir, considerando-se que será elaborada uma enquête, é escolher a amostra junto à população que se deseja estudar.

\section{2 - Sobre a escolha da amostra: a questão da representatividade}

O passo que segue a definição dos objetivos da investigação diz respeito à escolha da amostra junto à população-alvo que se deseja investigar e quais os meios disponíveis para se chegar a essas pessoas ou organizações ou enfim, elementos integrantes da amostra, e, a partir daí, definir que tipo de enquête será elaborada (tamanho, forma de aplicação, entre outros).

É necessário refletir sobre como obter um contato com o público-alvo da investigação, ou seja, como chegar àqueles indivíduos que detêm as respostas das questões que desejamos investigar. Eles serão interrogados por telefone ou por entrevistadores? O envio pelo correio irá depender do grau de precisão das questões formuladas; já por telefone estas devem ser curtas. Com entrevistadores, ao contrário, se tem a certeza de trazer informações úteis. Ao mesmo tempo, o entrevistador é alguém que poderá perturbar, exercendo pressão. É uma reflexão complexa, exigindo dedicação para se organizar corretamente a coleta das informações (MOSCAROLA, 1991).

4 Este tema é abordado por KOTLER (1991), MISHLER (1991), FOWLER (1993), e por FRANKFORT-NACHMIAS e NACHMIAS (1996). 
Em se tratando de pesquisa de mercado, deve-se interrogar o maior número possível de clientes potenciais, e, na empresa, deve-se interrogar todos os funcionários de todos os níveis, ou então contentar-se com uma simples sondagem, escolhendo apenas uma parte da população. A estatística permite economizar as interrogações exaustivas.

Serão abordadas, resumidamente, algumas indicações sobre os princípios a serem seguidos para implementar uma sondagem, a partir da observação de uma parte da população.

Começa-se pela forma mais conhecida de amostragem: a aleatória. Uma sondagem aleatória é uma sondagem na qual cada pessoa da população total tem teoricamente a mesma probabilidade de ser interrogada. Teoricamente é fácil fazer esta colocação. Na prática, é quase impossível se realizar. Vejamos por exemplo: o "homem" da rua não é um homem, é uma mulher nos países onde os homens trabalham mais e onde as mulheres cuidam do lar. Essa expressão "homem da rua", utilizada nas sondagens que são feitas a campo, é uma expressão na realidade falsa, pois o homem da rua não representa o caráter aleatório. Somos então, levados a proceder de outra maneira, interrogando quem se puder interrogar e onde for possível fazê-lo. Desse modo, serão obtidas amostras que não são modelos reduzidos da população total, compostas por estratos em proporções diferentes da proporção da população total.

Será necessário então, desejando-se raciocinar com a população em seu conjunto, realizar o que se chama de 'retificação' ou ajuste, ou seja, restabelecer as proporções da amostra em harmonia com a proporção da população total. Se essas condições forem reunidas é possível então, analisando-se a amostra, conhecer as propriedades da população total. Estas propriedades serão conhecidas com uma precisão maior ou menor de acordo com o tamanho da amostra. Este é o segundo ponto a ser observado.

Quanto ao número de pessoas ou organizações que serão interrogadas, segundo a chamada "Lei do Grande Número", não é razoável interrogar-se poucas. Este é um importante passo no contexto destas argumentações. Considera-se que, se não se questionou no mínimo $30 \%$ das pessoas, o que foi levantado é muito particular para que possa servir como referência para estimar o comportamento da população total. Mas, estatisticamente, a partir de uma amostra de somente 30 pessoas, SE formos indulgentes (ou indolentes), pode-se fazer uma estimativa e prever, ainda que de forma grosseira, a partir do que se observa na amostra, o que se passa na população total (desconhecida). FRANKFORTNACHMIAS e NACHMIAS (1996), e também PERRIEN, CHÉRON e ZINS (1984, cap. 7) desenvolvem este tema sobre amostragem.

Esta estimativa, contudo, tem algumas armadilhas e erros. Quanto maior o número de pessoas interrogadas, melhor será a precisão dos dados coletados. Se passarmos de 50 para 300 pessoas, o índice de erros dos dados coletados cai e ganha-se muito. Por outro lado, passando-se de 1000 para 2000 pessoas, ganha-se bem menos. Cabe realizar cálculos econômicos sobre o custo da interrogação, por um lado, e o custo do erro resultante de informações que podem levar a decisões errôneas, por outro lado. Quando se trata, por exemplo, de fazer uma sondagem sobre audiência da mídia publicitária, sobretudo na TV, é importante estar atento, pois são estas informações que irão fornecer cálculos de tarifas e de preços da publicidade. A precisão é fundamental neste caso. O que está em jogo é o valor da informação que se deseja obter.

Estas considerações irão levar à tomada de decisões relativas à escolha da amostra: quem interrogar? Como? Quantas pessoas interrogar? Essa primeira fase é muito importante e apresenta 
dificuldades, pois requer um certo trabalho para o qual a estatística dá indicações algumas vezes insuficientes. Entretanto, é interessante ter noções fundamentais para realizar esta etapa da melhor maneira possível.

Uma vez que foi determinada a amostra, passa-se ao segundo ponto, que é saber o que, exatamente, será perguntado tendo em vista os objetivos traçados no início da investigação.

\section{4 - SOBRE A CONCEPÇÃO DE UMA ENQUÊTE: a formulação das questões}

A partir dos objetivos traçados e do público-alvo que se deseja atingir elaboram-se as perguntas que irão buscar a resposta para as grandes questões de investigação. É recomendável algumas reflexões básicas nesta etapa, tais como: o que realmente desejamos saber junto ao público-alvo? Conhecer sua identidade? Sondar seu comportamento? Tentar entender suas motivações em determinadas atitudes? Ou tentar perceber ou captar algo em relação aos seus valores, opiniões e crenças em relação a algo mais específico? A partir disso deve ser elaborada uma estratégia de ação que deve permear a elaboração da maioria das perguntas. Estas indagações estão ilustradas na Figura 3.

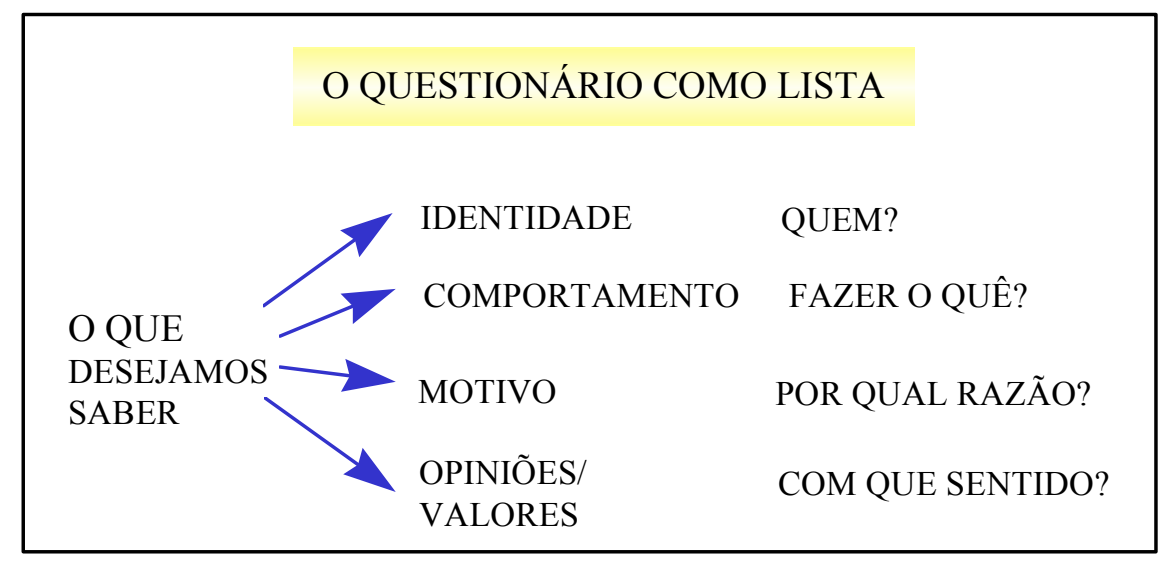

Figura 3 - Os objetivos observados na concepção de um questionário

As questões a serem levantadas são organizadas na forma de um questionário. Para isto, propõese um modelo que poderá auxiliar esta tarefa, um modelo de bom senso. O primeiro passo irá buscar determinar qual a identidade das pessoas que se quer interrogar, e é em função desta identidade que se poderá agir sobre elas. Procurar-se-á saber o que fazem, qual é o seu comportamento e, em função desse comportamento, ajustar a ação da empresa ou dos interessados na pesquisa.

Pode-se tratar, por exemplo, de uma atividade onde se busca um direcionamento para uma ação publicitária que lança um serviço de marketing. O que as pessoas fazem? Quais são as suas motivações, seu raciocínio? E, principalmente, porque elas agem desta forma? É o momento de buscar as razões do comportamento dos entrevistados. Quais são as suas opiniões, como reagem em relação ao produto, em relação à empresa... Contudo, não basta pensar "quem faz o quê" e "porque razão", de forma independente. Cada ponto é tomado e comparado com os demais, pois na verdade, identidade, opiniões/valores e comportamentos se interrelacionam estreitamente. 


\section{1 - Questões fechadas vs. questões abertas: as diferentes formas e o porquê de se 'abrir' um questionário}

Quando se constrói um questionário, fabrica-se um captador, um instrumento que vai nos colocar em contato com aquele que responde. Essa interação é condicionada pelo que permitiu fabricar o questionário, o que nos dá o modelo, a imagem. Esta imagem é uma aproximação do fenômeno que depende do equipamento de interpretação. Este equipamento é o que chamamos de teorias, conceitos, hipóteses, tudo o que já se conhece antes de iniciar a observação. A observação consiste apenas em ajustar a realidade ao que já se sabe. O ajuste vai depender da qualidade das informações que se possui previamente. É, portanto, a pré-concepção que condiciona o resultado. Normalmente, quando se fecha uma questão, quando se fabrica e se estrutura um questionário, dá-se apenas uma pequena escolha para que os respondentes dêem a sua opinião sobre determinado assunto.

Ao invés de oferecer apenas algumas alternativas de opinião, poderia-se entregar às pessoas uma folha em branco e solicitar-lhes que discorram sobre o assunto ' $X$ '. Este exercício, contudo, é um tanto difícil, tomando tempo e podendo aborrecer os respondentes, a menos que lhes fossem dadas condições muito favoráveis. Se essas condições tivessem sido oferecidas, eles teriam escrito uma ou duas páginas com seu estilo próprio e suas idéias particulares. Estaríamos, então, frente a um embaraço para analisar todos estes textos. É por isso que se oferecem questões fechadas: porque são mais simples para se obter uma resposta e porque é mais simples analisar as respostas. Contudo, ao adotá-las, corre-se um risco significativo de simplesmente ficar-se cego (ou muito limitado) com o que já se sabe.

O céu tem a forma da janela. Imaginemos que fechamos alguém no início de sua vida em uma casa onde lhe é ensinado a geometria, a ciência e a geografia e que se diz a ele: "quando você tiver doze anos poderá conhecer o mundo". E no dia em que ele chega aos doze anos se abre a janela e se pergunta: qual é a forma do céu? Conhecendo a geometria e vendo o céu através de uma janela vai se dizer que ele é oval ou retangular. O que dá a forma do céu é a arquitetura da casa, neste exemplo. O que dá a resposta ao questionário é a concepção desse questionário. Ele é como uma janela que se abre sobre o mundo e quando se olha através desta janela, se tem a forma dos conhecimentos adquiridos previamente. É por isso que muitas vezes é útil não fechar a janela; deixá-la bem aberta, ou deixar pelo menos algumas aberturas. Deixar algumas aberturas é introduzir no questionário questões abertas, tentando captar alguns dados mais espontâneos, menos previsíveis, enfim.

Pode-se acrescentar uma pergunta aberta no final de um questionário estruturado: finalmente, o respondente teria algo mais a dizer; ou então oferecer uma folha em branco e deixar que ele se expressasse em total liberdade. Ou ainda perguntar, no início da enquête: "quais são as palavras que lhe vêm espontaneamente à mente quando se fala sobre o assunto ' $X$ '?”, sem influenciá-lo pelas palavras que foram escolhidas para definir as escalas.

Em resumo, acaba-se de definir três protocolos, ou seja, três maneiras de se abrir um questionário.

Tomando-se, por exemplo, o assunto 'casamento':

1. Fazer perguntas sob a seguinte forma: "que palavras lhe vêm à mente quando o assunto é casamento"? 
2. Podemos solicitar: "defina o casamento em algumas frases."

3. Em terceiro nível, podemos pedir uma dissertação, uma argumentação sobre o casamento, um pequeno romance. E aí colocaremos o respondente em uma dificuldade ainda maior.

Tentando coletar palavras estamos apenas ao nível do léxico; tentando coletar frases, se acrescenta a sintaxe: as palavras terão seu sentido afetado pela maneira como se constrói a frase. Em um nível mais complexo está a produção de um discurso: junto à sintaxe se apresentará a argumentação, a retórica, toda uma construção. No decorrer deste artigo serão apresentados alguns exemplos de enquêtes onde se introduziu questões abertas e como elas podem ser analisadas de uma forma acessível.

Feitas as considerações sobre o planejamento e a concepção do instrumental de uma investigação, parte-se para a apresentação de casos práticos que ilustram o uso de métodos de análise quantitativas e qualitativas de dados ${ }^{5}$.

\section{ANÁLISE QUANTITATIVA DE DADOS: quem é e o que deseja o consumidor: a enquête do "Turista do Lago"}

Nesta seção, é apresentado um exemplo de enquête essencialmente quantitativa, o caso do "Turista do lago". Eis uma pequena 'ficha técnica' desta enquête (Figura 4):

\begin{tabular}{|l|l|}
\hline \multicolumn{3}{|c|}{ FICHA TÉCNICA DA ENQUÊTE } \\
\hline INTERESSADOS & $\begin{array}{l}\text { Prefeitura de uma cidade (região de lagos, Genebra, Suíça) que deseja } \\
\text { desenvolver o turismo como atividade econômica na região. }\end{array}$ \\
\hline \multirow{2}{*}{ OBJETIVOS } & $\begin{array}{l}\text { Saber: qual a infra-estrutura a ser disponibilizada (camping, hotel, etc) para } \\
\text { atrair turistas para a região. } \\
\text { Conhecer: } \\
\text { (1) Quem seriam os potenciais turistas; } \\
\text { (2) Qual a infra-estrutura a ser oferecida a estes turistas de acordo com suas } \\
\text { preferências (hotéis, campings, etc.). }\end{array}$ \\
\hline \multirow{2}{*}{ TMOSTRo de público-alvo } & \multicolumn{1}{c|}{ Quantidade } \\
\cline { 2 - 3 } & \multicolumn{2}{|c|}{ Turistas da região dos Lagos } & \multicolumn{1}{c|}{552 pessoas } \\
\hline
\end{tabular}

Figura 4 - A ficha técnica da enquête "Turista do lago"

Este estudo foi realizado há alguns anos, em uma região européia à margem do Lago, em Genebra, e respondia ao pedido da prefeitura de uma cidade que desejava desenvolver o turismo na região. Para isso, dispunham-se dos meios para subvencionar as instalações: hotéis, campings, equipamentos de lazer. Por outro lado, os serviços de turismo dessa região pretendiam lançar uma campanha publicitária em toda a França para atrair turistas para o local. As questões inerentes a este tipo de estudo têm por objetivo saber qual o turismo a ser desenvolvido: quem são os potenciais turistas? Qual a infra-estrutura a ser oferecida (hotéis, campings, alojamentos de aluguel)? As respostas visam atender às necessidades dos turistas e à economia regional.

\footnotetext{
5 O sistema usado para a concepção das enquêtes, a entrada ou importação dos dados, e para a análise uni, bi e multivariada dos dados quantitativos e qualitativos é o Sphinx Léxica ® (FREITAS, 1993; FREITAS, CUNHA e MOSCAROLA, 1996 "a" e "b"; SPHINX LEXICA, 2001; FREITAS e MOSCAROLA, 2000; FREITAS e JANISSEK, 2000).
} 
A partir daí, subquestões são elaboradas: o que os potenciais turistas fazem? E, sobretudo, como gastam seu dinheiro? Existe uma categoria de turistas que gasta mais do que outra? As pessoas que estão no hotel são mais 'interessantes' do que as pessoas que ficam no camping? Responder a estas perguntas permitirá esclarecer e orientar decisões de investimentos. Por fim, é preciso atrair os turistas. Quais os argumentos a utilizar? Como fazer com que eles tenham uma imagem positiva da região? Para isso se buscou saber o que as férias representam para os mesmos. Sendo possível identificar esses sentimentos ou posicionamentos e relacioná-los aos diversos tipos de turismo, isto certamente poderá levar ao planejamento de uma comunicação de marketing mais eficaz (Figura 5).

Eis o raciocínio que esteve na origem da enquête que aqui está sendo abordada: a amostra era composta por 552 pessoas; essas pessoas eram turistas da região dos lagos, um público com uma certa experiência em turismo nessa região. As pessoas entrevistadas foram classificadas de acordo com os grandes tipos de alojamentos que utilizavam: (1) hotéis, (2) campings, (3) casas de aluguel, e ainda (4) residência de familiares ou amigos, o que permitiu ter aproximadamente 150 pessoas alojadas em cada uma dessas categorias. A escolha da amostra foi aleatória.

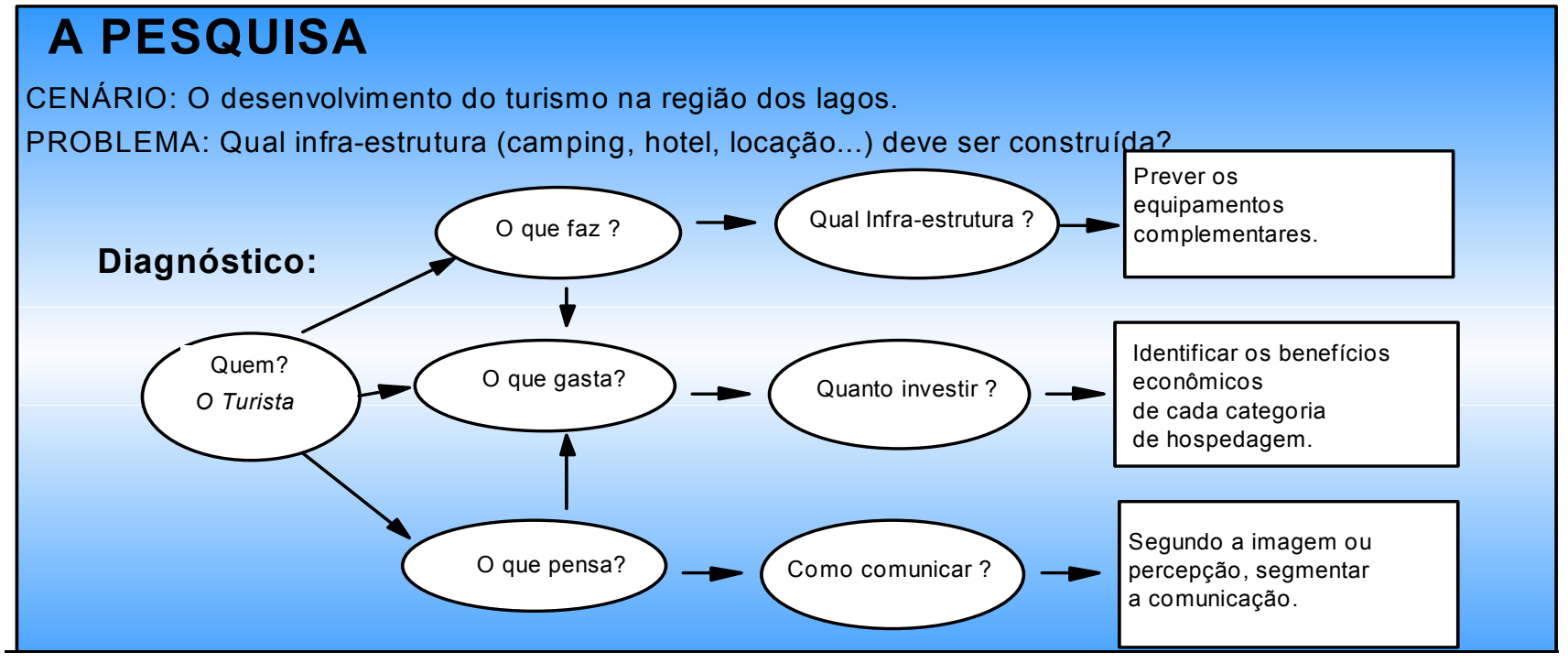

Figura 5 - A enquête do "Turista do Lago"

\section{1 - O questionário}

Uma parte do questionário aplicado (o original contém um total de 70 perguntas) é assim ilustrada:

$\Rightarrow$ Quais são as 3 primeiras razões que o fizeram escolher nossa região? (paisagem, clima, natureza, montanha, animação, ...)

$\Rightarrow$ Quais são suas principais atividades na região? (descansar, banhos, lazer, tênis, ...)

$\Rightarrow$ Você poderia estimar seus gastos por pessoa realizados durante sua estadia na região? (hospedagem, supermercado, restaurante, lazer, ...)

$\Rightarrow$ Qual o tipo de hospedagem preferido? (hotel, camping, aluguel, família/amigos, ...)

$\Rightarrow$ Questões de perfil (sexo, idade, profissão, ...) 


\subsection{2 - O tratamento dos dados coletados}

Após a aplicação do questionário e a digitação dos dados, chega-se à etapa de tratamento ou processamento dos dados, decidindo-se também sobre a escolha dos tipos de análise a serem realizadas, o que pode ser feito dentre as ilustradas na Figura 6.

Partindo-se do simples para o complexo, é possível analisar os resultados das 552 respostas através do que se chama de análise univariada, um método simples. Podem ser examinadas as respostas para cada uma das perguntas, uma após a outra, variável por variável. É a tabulação simples dos dados.

\section{AS TÉCNICAS DE ANÁLISE DE DADOS}

Análise univariada, tab. simples

Descrever uma variável por vez

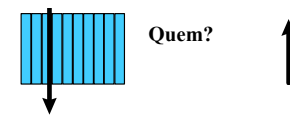

Análise bivariada, tab. cruzada

Relacionar 2 variáveis, explicar
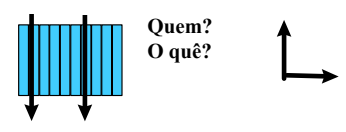

Análise multivariada, tab. múltipla

Analisar simultaneamente

diversas variáveis, sintetizar
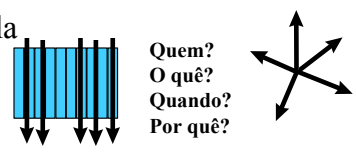

Figura 6 - As técnicas de análise de dados

De uma maneira mais complexa pode ser feita uma análise bivariada, onde se buscará saber quais as relações entre a resposta a uma pergunta (por exemplo a hospedagem) e a resposta a outra questão (como por exemplo o gasto). É a tabulação cruzada ou cruzamento.

Por fim, pode ser utilizado um método mais sofisticado, a análise multivariada, que consistirá em analisar globalmente um conjunto de perguntas (variáveis), o que será feito para se tentar resumir a opinião dos turistas. A seguir, será visto como realizar essas análises, não exaustivas, mas sim a título ilustrativo, de uma maneira prática, com a utilização de uma ferramenta adequada.

\section{$\Rightarrow$ Análise univariada}

O primeiro passo da análise será o tratamento univariado. No caso apresentado, sobre a primeira questão "Quais são as três primeiras razões que lhe fizeram escolher nossa região?”, a paisagem é uma razão citada por 252 pessoas, o que representa $46 \%$ dos 552 entrevistados e ao mesmo tempo $15 \%$ de todas as razões escolhidas. Neste primeiro nível pode-se reconstituir as respostas, questão por questão. (Figura 7). Pode-se escolher os totais e percentuais em relação ao número de indivíduos entrevistados ou em relação ao total de citações ou de escolhas naquela questão.

\begin{tabular}{|c|r|r|}
\hline RAZÃO ESCOLHA & No. cit. & \multicolumn{1}{c|}{ Freq. } \\
\hline Lago & 272 & $17 \%$ \\
\hline Paisagem & 252 & $15 \%$ \\
\hline Montanha & 184 & $11 \%$ \\
\hline Tranqüilidade,Repouso & 149 & $9 \%$ \\
\hline Região de Renome & 128 & $8 \%$ \\
\hline Estada Precedente & 122 & $7 \%$ \\
\hline Outras (clima, \$, etc) & 517 & $32 \%$ \\
\hline Não-respostas & 4 & $0 \%$ \\
\hline TOTAL & 1628 & $\mathbf{1 0 0} \%$ \\
\hline
\end{tabular}

Figura 7 - A tabulação simples da variável "Razão da Escolha"

Desdobrando-se automaticamente o conjunto das respostas, pode-se verificar, por exemplo, como se comportou a variável "Gastos Totais" (Figura 8). Percebe-se que a maioria dos turistas (245 
pessoas) se encontra nas 2 faixas de gastos totais que cobrem de 1000 a 5000 francos franceses, enquanto apenas uma minoria (46 pessoas) gasta mais do que 6000 francos.

\begin{tabular}{|c|c|c|c|c|c|}
\hline GASTOS TOTAIS & No. cit. & Freq. & GASTOS TOTAIS_C & No. cit. & Freq. \\
\hline Não-resposta & 205 & $37 \%$ & Não declararam gastos & 205 & $37 \%$ \\
\hline menos de 5150 & 300 & $54 \%$ & menos de 1000.00 & $--\overline{40}$ & $\overline{7} \overline{\%}$ \\
\hline de 5150 a 10300 & 31 & $6 \%$ & de 1000.00 a 2500.00 & 112 & $20 \%$ \\
\hline de 10300 a 15450 & & $1 \%$ & 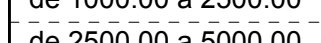 & -125 & -20 \\
\hline de 15450 a 20600 & & $1 \%^{-}$ & de 2500.00 a 5000.00 & 133 & $24 \%$ \\
\hline de 20600 a 25750 & & $\overline{0} \%^{-}$ & de 5000.00 a 6000.00 & 16 & $3 \%$ \\
\hline 25750 e acima & 2 & $0 \%$ & 6000.00 e acima & 46 & $8 \%$ \\
\hline TOTAL OBS. & 552 & $100 \%$ & TOTAL OBS. & 552 & $100 \%$ \\
\hline \multicolumn{3}{|c|}{$\begin{array}{l}\text { Mínimo }=0, \text { Máximo }=30900 \\
\text { Soma }=1242102 \\
\text { Média }=3579.5 \text { Desvio-padrão }=3935.9\end{array}$} & \multicolumn{3}{|c|}{ Média= 2.8 Desvio padrão= 1.1} \\
\hline
\end{tabular}

\section{Figura 8 - A criação de classes para a variável "Gastos Totais",}

\section{$\Rightarrow$ Análise bivariada}

Na Figura 9, apresenta-se uma análise envolvendo a relação existente entre duas variáveis. Ajustando a divisão das despesas de acordo com grupos que nos interessam, cria-se uma nova variável a ser acrescentada ao estudo, chamada "classe de despesas" (gastos totais baixos, médios ou altos). O que importa neste caso é saber se há uma relação entre o nível de gastos e o tipo de hospedagem. Inicia-se então a análise bivariada. Colocam-se em relação e cruzam-se duas variáveis: de um lado o tipo de hospedagem e de outro as classes de despesas. Eis o resultado:

\begin{tabular}{|c|c|c|c|c|c|}
\hline Gastos totais & Hotel & Camping & Aluguel & $\begin{array}{l}\text { Famílial } \\
\text { Amigos }\end{array}$ & TOTAL \\
\hline Baixos & 7 & 28 & 21 & 44 & $100 \%$ \\
\hline Médios & 24 & 14 & 29 & 33 & $100 \%$ \\
\hline Altos & 35 & 9 & 35 & 21 & $100 \%$ \\
\hline TOTAL & $18 \%$ & $19 \%$ & $26 \%$ & $36 \%$ & $100 \%$ \\
\hline
\end{tabular}

Figura 9 - Análise bivariada "Tipo de hospedagem x Classes de despesas"

Isto permite concluir que as pessoas que se hospedam em casa de família/amigos são as que menos gastam. As despesas médias são efetuadas pelas pessoas que se hospedam entre casa de aluguel e casa de família/amigos. Já as despesas mais altas são efetuadas entre quem se hospeda em casa de aluguel e, principalmente, em hotéis.

\footnotetext{
6 Os intervalos nas tabelas são sempre "abertos à direita", ou seja "de 5150 a 10300" não inclui o valor exato 10300 , o qual estará no início do próximo intervalo.
} 


\section{$\Rightarrow$ Análise de Correspondência (AC)}

Pode-se fazer ainda outros tipos de análise com diferentes recursos; uma das que possui maiores recursos visuais é a de Análise de Correspondência (CUNHA Jr., 1998). A mesma análise realizada anteriormente pode se tornar mais clara através da utilização desta técnica. Observe o mapa apresentado na Figura 10, que coloca os grupos de gastos em uma lógica de proximidade com os tipos de hospedagem.

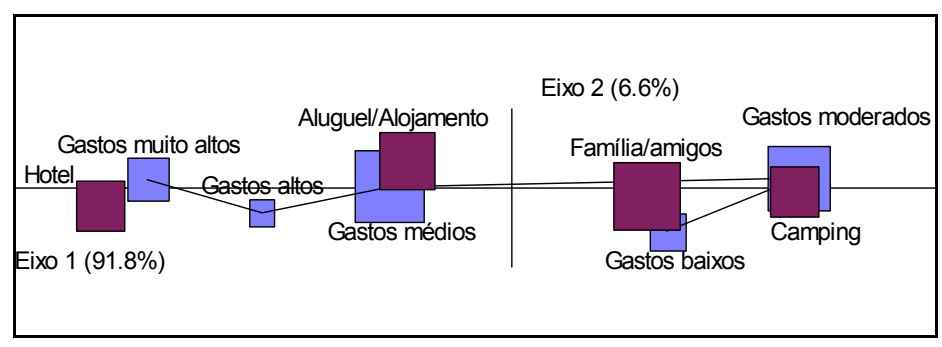

Figura 10 - Análise de correspondência "Gastos x Tipo de hospedagem"

Vê-se uma confirmação da análise realizada sobre a tabela: hotel está próximo da classe com nível de despesas elevado, enquanto que família/amigos e camping está próximo da classe de baixos níveis de despesas. Um nível intermediário de despesas está próximo da casa de aluguel.

A técnica utilizada apresenta a vantagem de mostrar muito rapidamente as particularidades que aparecem em um quadro de exame de percentuais. É a visualização da vantagem ou do problema, a qual suscitará a curiosidade do analista ou do decisor. Utiliza-se esta análise em um outro exemplo: há uma diferença entre as atividades dos turistas segundo o tipo de hospedagem? Faz-se o teste e chega-se ao seguinte quadro (Figura 11):

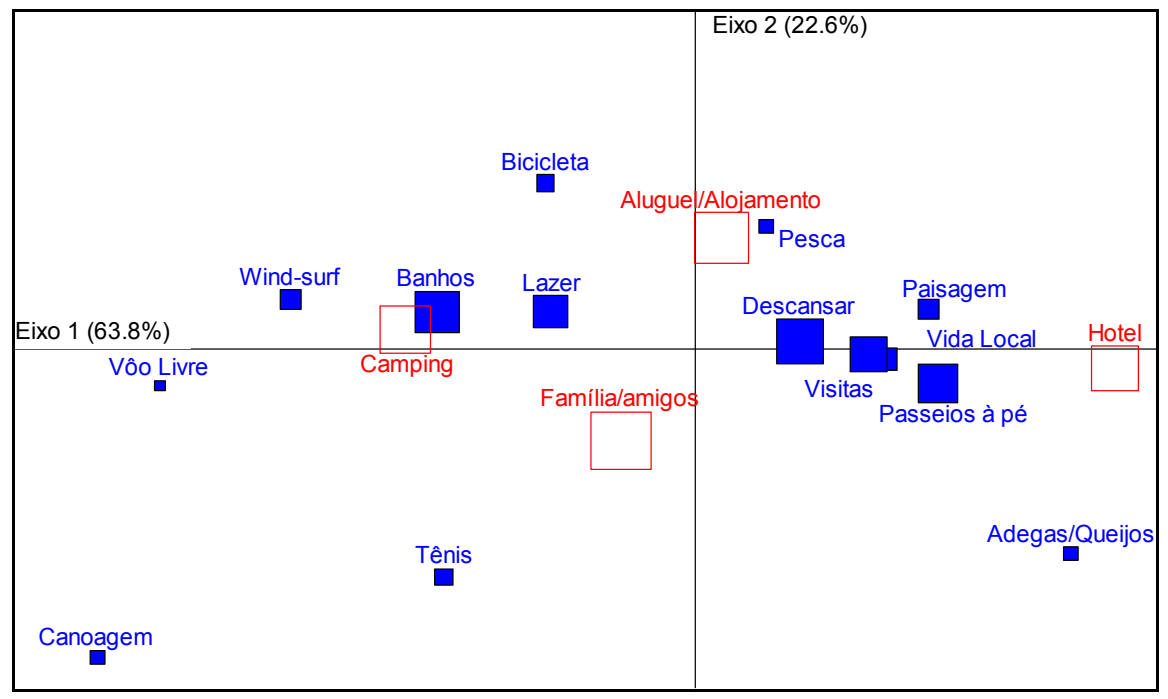

Figura 11 - Análise de correspondência "Tipo de hospedagem x Atividade"

Percebe-se que ao lado do camping tem-se banho, tênis, windsurf, equitação, atividades intensas, esportivas, enquanto que, ao lado do hotel, encontra-se gastronomia, passeios a pé; atividades bem mais moderadas. Descobre-se, por fim, que entre o hotel e o camping há uma diferença de natureza econômica mas há também uma diferença de atividade. Como pode ser visto rapidamente, a Análise de 
Correspondência permite tomar conhecimento, com mais clareza, de quadros ou tabelas a princípio difíceis de serem analisados ${ }^{7}$.

\section{$\Rightarrow$ Relação entre as médias das variáveis, análise das diferenças e dos perfis}

A seguir, compara-se as médias dos gastos: gastos totais, com hospedagem, alimentação (supermercado), restaurante, lazer e diversos, bem como a duração média em dias e ainda a idade dos respondentes, com a variável "tipo de hospedagem". Desse modo, busca-se identificar onde cada categoria de turista (segundo a hospedagem) realiza seus maiores gastos, bem como alguns dados sobre duração da estadia e idade. Chega-se ao resultado da Figura 12:

\begin{tabular}{|c|c|c|c|c|c|c|c|c|c|}
\hline IPO DE HOSPEDAGE & $\begin{array}{l}\text { 3.GASTOS } \\
\text { TOTAIS }\end{array}$ & \begin{tabular}{|c|} 
4.GASTOS \\
OSPEDAGE
\end{tabular} & \begin{tabular}{|l|} 
5.GASTOS \\
LIMENTACÃ
\end{tabular} & $\begin{array}{l}\text { 6.GASTOS } \\
\text { RESTAUR }\end{array}$ & \begin{tabular}{|c|} 
7.GASTOS \\
VESTUÁRIO
\end{tabular} & $\begin{array}{l}\text { 8.GASTOS } \\
\text { LAZER }\end{array}$ & $\begin{array}{l}\text { 9.GASTOS } \\
\text { DIVERSOS }\end{array}$ & $\begin{array}{c}\text { 2.DURAÇĀq } \\
\text { ESTADA }\end{array}$ & 14.IDADE \\
\hline Hotel & 5007.3 & 1776.3 & 445.7 & 830.6 & 293.2 & 479.7 & 264.9 & 3.4 & 45.8 \\
\hline Camping & 2490.0 & 604.6 & $\overline{7} \overline{7} 6 . \overline{5}$ & 342.3 & 100.0 & 390.6 & 311.4 & 17.8 & 31.6 \\
\hline Aluguel/Älojamento & 4643.3 & 1415.6 & 944.5 & 385.0 & 234.0 & 544.8 & 633.9 & $18 . \overline{6}$ & 35.0 \\
\hline Família/amigos & $2 \overline{803.7}$ & 229.6 & 498.3 & 348.6 & 272.7 & 470.0 & $\overline{275} \overline{5} . \overline{9}$ & 18.2 & $3 \longdiv { 1 . 4 }$ \\
\hline CONJUNTO & 3579.5 & 904.6 & 656.9 & 449.2 & 233.4 & 470.8 & 362.8 & 17.3 & 35.0 \\
\hline
\end{tabular}

Figura 12 - Relações entre as médias das variáveis inerentes a gastos e o tipo de hospedagem

No quadro acima lê-se cada uma das despesas e suas respectivas médias, bem como pode-se verificar que a permanência em hotel é pouco menor que nos outros tipos de alojamento e que são os de maior idade média que lá se hospedam. Percebe-se que alguns títulos de variáveis são marcados em azul e outros em preto: o que se faz é um estudo do Desvio-Padrão para testar se é possível dizer que, do ponto de vista de despesa total, há uma diferença nas diferentes hospedagens. A resposta é positiva para algumas das despesas, cujas colunas estão marcadas em azul, como por exemplo hospedagem, alimentação e restaurante. Muito embora as despesas não sejam excessivamente diferentes da média do conjunto nos itens alimentação e restaurante, os gastos com hospedagem mostram forte discrepância em cada tipo de alojamento (1776 em hotel e 229 em casa de amigos), comparados com a média do conjunto (904).

Caso o analista tenha interesse na variável "hospedagem" que se mostrou discriminante no geral (coluna azul), e apresenta valores extremamente diferentes da média do conjunto, pode-se tentar avaliar mais detalhadamente este dado pelo seu perfil, como mostra a Figura 13. Nota-se que se pode falar categoricamente sobre o tipo de alojamento "família/amigos", um pouco mais moderadamente sobre "camping" e deve-se avaliar melhor o que se poderia afirmar sobre os outros tipos de alojamento.

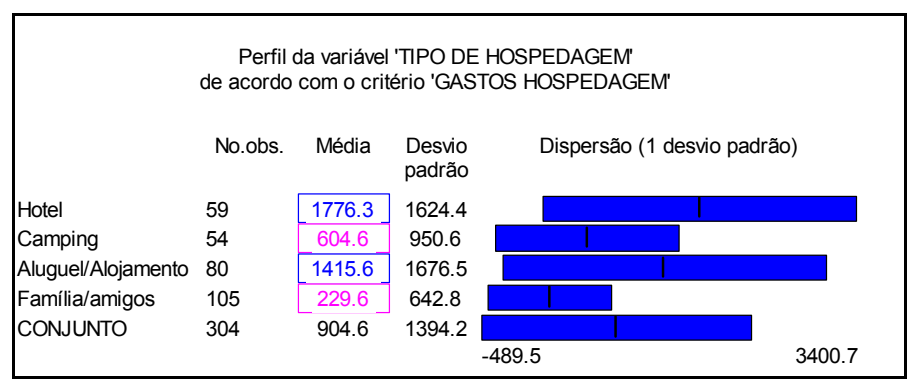

Figura 13 - Perfil do tipo de hospedagem x gastos hospedagem

Enfim, provavelmente para o responsável pelo clube de tênis é indiferente saber se iremos oferecer aos turistas um hotel ou um camping, visto que os gastos com lazer são equilibrados, mas ele

7 CUNHA Jr (1998) elaborou uma revisão sobre o tema, devendo-se destacar CARROL, GREEN e SCHAFFER (1986, 1987) e também HOFFMAN e FRANKE (1986). 
ainda poderia já começar a preferir que fosse um hotel ao invés de um camping, visto que os turistas do hotel gastam um pouco mais com lazer. Contudo o dono do supermercado (alimentação), por sua vez, estaria bem mais interessado nesta informação, pois poderia voltar-se para os turistas do camping e de aluguel; enquanto o dono do restaurante se interessaria pelo hoteleiro e pelas pessoas que se hospedam no hotel. Procura-se, a seguir, analisar as despesas mais significativas. Naturalmente, uma vez com os dados coletados, diversas análises poderiam ser realizadas, com diferentes enfoques, como o dos turistas mais idosos versus os mais jovens, os de estadia de curta duração versus os de longa duração, os de atividades mais esportivas e os de atividades mais moderadas, e assim por diante, permitindo levantar diferentes perfis dentro da amostra.

\section{$\Rightarrow$ Análise multivariada}

Faz-se a seguir a chamada análise multivariada; colocando-se os diversos tipos de hospedagens em relação umas com as outras e em relação às despesas, trata-se aqui de uma Análise de Componentes Principais (ACP). No gráfico apresentado ao lado, Figura 14, vê-se que as pessoas que estão no hotel gastam muito em restaurantes e em vestuário, gastam bastante em hospedagem e têm uma despesa total alta. As pessoas que estão no camping ou em casa de família e amigos gastam pouco com hospedagem (estão do lado oposto no gráfico). Por outro lado, as pessoas que estão na casa de família/amigos ou no camping são aquelas que gastam um pouco mais em alimentação, ao passo que as pessoas que alugam casas são as que gastam mais em alimentação e têm outras despesas diversas.

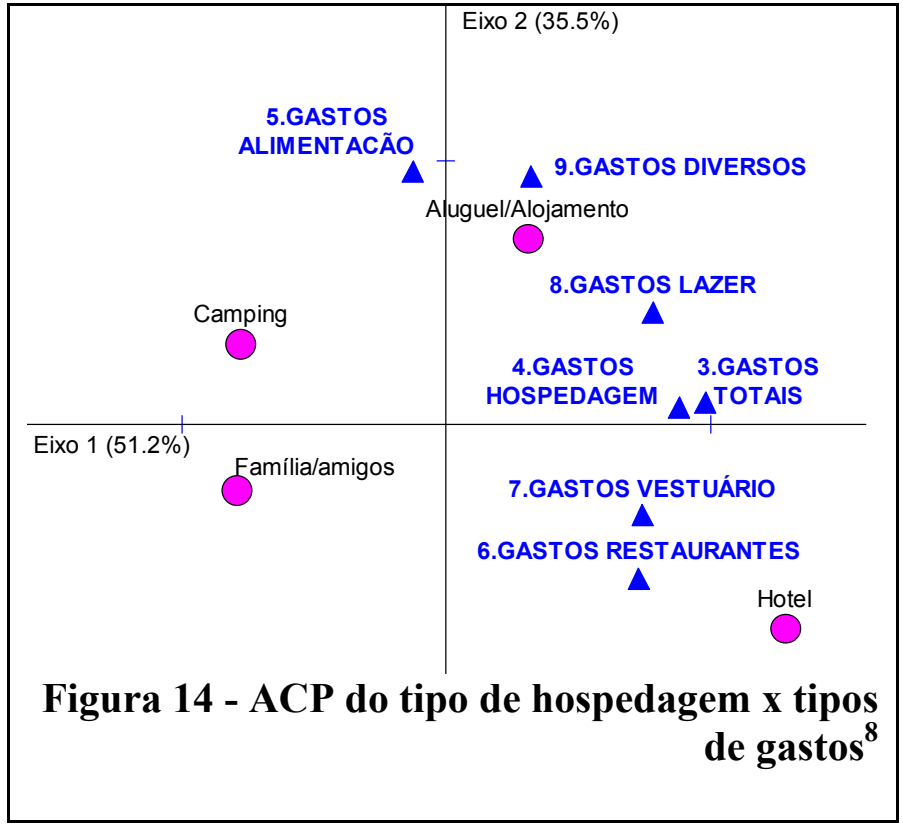

\section{3 - Conclusões e comentários sobre o caso do "Turista do Lago"}

A representação gráfica se mostra interessante, pois pode-se representar cada um dos indivíduos, chegando-se a grandes grupos. $O$ perfil de cada grupo irá determinar o tipo de produto/serviço/preço/comunicação a serem apresentados. Aos que gostam de movimento, mostra-se uma região viva, animada, cheia de sol. Aos que gostam de tranqüilidade, mostra-se a natureza, um hotel calmo. Para as pessoas econômicas, mostra-se que por pouco dinheiro se oferecem diversas atrações, e assim por diante.

A partir das análises apresentadas, pode-se construir diferentes perfis dos turistas da região, o que gera uma informação valiosa para as empresas que desejam segmentar e direcionar seus esforços comerciais e de comunicação. Contudo, partindo-se para a realidade na qual surgiu a enquête, quando da conclusão final do estudo, houve fatores inesperados, conjunturais: as decisões de investimentos consistiram não em promover os hotéis ou campings (formas de hospedagem que poderiam ser estudadas) e sim, promover os aluguéis por motivos de ordem política e não econômica.

\footnotetext{
${ }^{8}$ Gráfico gerado a partir da tabela apresentada na figura 12. 
Em contrapartida, no que tange à comunicação, as análises aqui realizadas foram integradas em todo o processo criativo da agência que produziu os cartazes e as comunicações publicitárias destinadas à promoção do turismo naquela região dos Lagos. A análise dos dados trouxe, portanto, informações que tornaram mais eficaz a estratégia de comunicação adotada para promoção do turismo na região, o que atende aos objetivos dos interessados na enquête. A seguir apresenta-se um novo caso de enquête, desta vez estreitamente relacionada à investigação de valores/opiniões de um determinado público frente a um assunto em específico.

\section{ANÁLISE QUALITATIVA DE DADOS}

A seguir são apresentados exemplos de esquetes que apresentam questões abertas, qualitativas, e como foram realizadas as suas respectivas análises. Após uma ilustração prática inicial, desenvolvemse alguns conceitos sobre análise de conteúdo e análise lexical (com o devido referencial), entre outros.

\section{1 - A questão da qualidade vista por diversas empresas: o caso da pesquisa sobre "Indicadores de Qualidade e Produtividade"}

Para ilustrar algumas formas de análise de questões abertas nas enquêtes, inicia-se com uma pesquisa realizada junto a diretores da área industrial e de recursos humanos de 120 empresas gaúchas, realizada em 1994, numa parceria entre o SEBRAE/RS, FIERGS (IEL), com coordenação do PPGA/UFRGS (RUAS, PIRES, FREITAS, ANTUNES \& CUNHA, 1994), sobre Indicadores de Qualidade e Produtividade. A título de ilustração, serão tratadas apenas algumas poucas variáveis contidas nessa pesquisa.

\begin{tabular}{|l|l|c|}
\hline \multicolumn{3}{|c|}{ FICHA TÉCNICA DA ENQUÊTE } \\
\hline $\begin{array}{l}\text { INTERESSADO } \\
\text { S }\end{array}$ & \multicolumn{2}{|c|}{ SEBRAE, FIERGS, IEL/RS, PPGA/UFRGS } \\
\hline \multirow{2}{*}{ OBJETIVOS } & $\begin{array}{l}\text { Verificar se as empresas gaúchas utilizam e como fazem uso de indicadores de } \\
\text { qualidade e produtividade. }\end{array}$ \\
\hline \multirow{2}{*}{ AMOSTRA } & $\begin{array}{l}\text { Trandes, pequenas e médias empresas } \\
\text { do estado do Rio Grande do Sul, Brasil }\end{array}$ & Quantidade \\
\cline { 2 - 3 } & & 120 empresas \\
\hline
\end{tabular}

\section{Figura 15 - Ficha técnica da enquête "Indicadores da Qualidade e Produtividade"}

Esta pesquisa teve por objetivo avaliar os Programas de Qualidade e Produtividade na indústria gaúcha (RS/Brasil). As 120 empresas que compõem a amostra são divididas entre 30 empresas pequenas, 30 médias e 60 grandes. As pessoas entrevistadas em cada empresa foram o diretor industrial e o diretor da qualidade ou de recursos humanos.

\section{$\Rightarrow$ Análise dos dados via análise lexical das questões abertas da enquête}

A seguir serão processados e analisados os textos das respostas às questões abertas. Primeiramente será examinada a seguinte questão:

Quais as etapas do processo de qualidade encontradas em sua empresa? 
Por se tratar de uma pergunta aberta, teve-se como resultado 120 pequenos textos, frases que definem, de acordo com os respondentes, as etapas do processo de qualidade em suas respectivas organizações. Alguns trechos podem ser vistos através da figura 16.

\section{QUALIDADE - Variável: 1. ETAPAS PROCESSO}

$\Rightarrow$ Treinamento no sistema de Qualidade. Gerenciamento da rotina. Gerenciamento das rotinas. 5Ss. Garantia Qualidade. Promover o crescimento do ser humano.

$\Rightarrow$ Reuniões de conscientização sobre a importância da qualidade. Pessoal mais qualificado (hierarquia superior) está se reunindo para debates sobre qualidade. Conscientização da importância de cada pessoa para o desenvolvimento da qualidade. Idéias vem de livros e vídeos assistidos pelos gerentes.

$\Rightarrow$ Troca de Diretoria. Diretor faz cursos/ ensina: encontro sinérgico anual. todos os operários desenvolvem. Times de Qualidade

$\Rightarrow$ Introdução do trabalho dos 5s (housekeeping). Introdução do Kaizen. Trabalhos de Grupos (gestão participativa).

$\Rightarrow$ Criado o CEP, a Qualidade e Produtividade vem sendo desenvolvidos.

$\Rightarrow$ Criação de um setor de controle de qualidade, conscientização, sensibilização e formação de 02 grupos melhorias.

\section{Figura 16 - Algumas respostas sobre "Etapas do processo de qualidade"}

Como analisar esses dados qualitativos? A respeito desta questão surgem outras, entre elas:

(1) Será que o interesse pela qualidade depende do tamanho da empresa? Será que as pequenas empresas ou grandes empresas manifestam o mesmo interesse pela qualidade?

(2) Será que a idéia de qualidade tem o mesmo significado para as empresas de pequeno porte e para as de grande porte?

Um primeiro método de análise lexical consiste em averiguar ou medir a dimensão das respostas: as pessoas responderam de forma extensa ou concisa? Cria-se uma hipótese de que aqueles que deram respostas extensas têm um interesse maior do que os demais. Uma hipótese discutível que dará, porém, uma indicação.

Nota-se então (Figura 17) que uma parte considerável $(27 \%)$ não respondeu, o que por si só é um indicador a investigar, mas também que $73 \%$ participaram com comentários, e que $50 \%$ tiveram uma participação bem "interessada", com mais de 17 palavras na descrição das etapas do processo.

\begin{tabular}{|c|c|c|}
\hline $\begin{array}{l}\text { Etapas do processo } \\
\text { tamanho (palavras) }\end{array}$ & No. cit. & Freq. \\
\hline Não-resposta & 32 & $27 \%$ \\
\hline menos de 17 & 27 & $23 \%$ \\
\hline de 17 a 31 & 33 & $28 \%$ \\
\hline de 31 a 60 & 23 & $19 \%$ \\
\hline mais de 60 & 5 & $3 \%$ \\
\hline TOTAL OBS. & 120 & $100 \%$ \\
\hline \multicolumn{3}{|c|}{$\begin{array}{l}\text { Mínimo= 2, Máximo= } 89 \\
\text { Soma= } 2345 \\
\text { Média= 26.6 Desvio-padrão= } 17.5\end{array}$} \\
\hline
\end{tabular}

Figura 17 - A quantidade de palavras por depoimento 
Num segundo momento iremos nos interessar pelo conteúdo das respostas. A análise pode ser realizada de duas maneiras: a análise de conteúdo e a análise lexical. A análise de conteúdo consiste em uma leitura profunda de cada uma das respostas, onde, codificando-se cada uma, obtém-se uma idéia sobre o todo. A outra maneira é a análise lexical, que consiste em se passar da análise do texto para a análise do léxico (o conjunto de todas as palavras encontradas nos depoimentos ou respostas).

A primeira parte da análise das respostas consiste na leitura dos textos. Vai-se lendo o texto correspondente a cada uma das empresas entrevistadas (parte superior da imagem à esquerda na Figura 18) e a seguir pode-se interpretar o conteúdo de forma a codificar as respostas dadas (parte inferior da mesma imagem), à medida que se lê o conteúdo da resposta em análise, pode-se criar as categorias de respostas as quais se deve marcar antes de passar ao próximo respondente. A tela da esquerda na Figura 18 apresenta o início de uma codificação que evolui naturalmente à medida que se avança na leitura de cada resposta e conseqüente criação de novos códigos ou categorias de respostas a marcar.

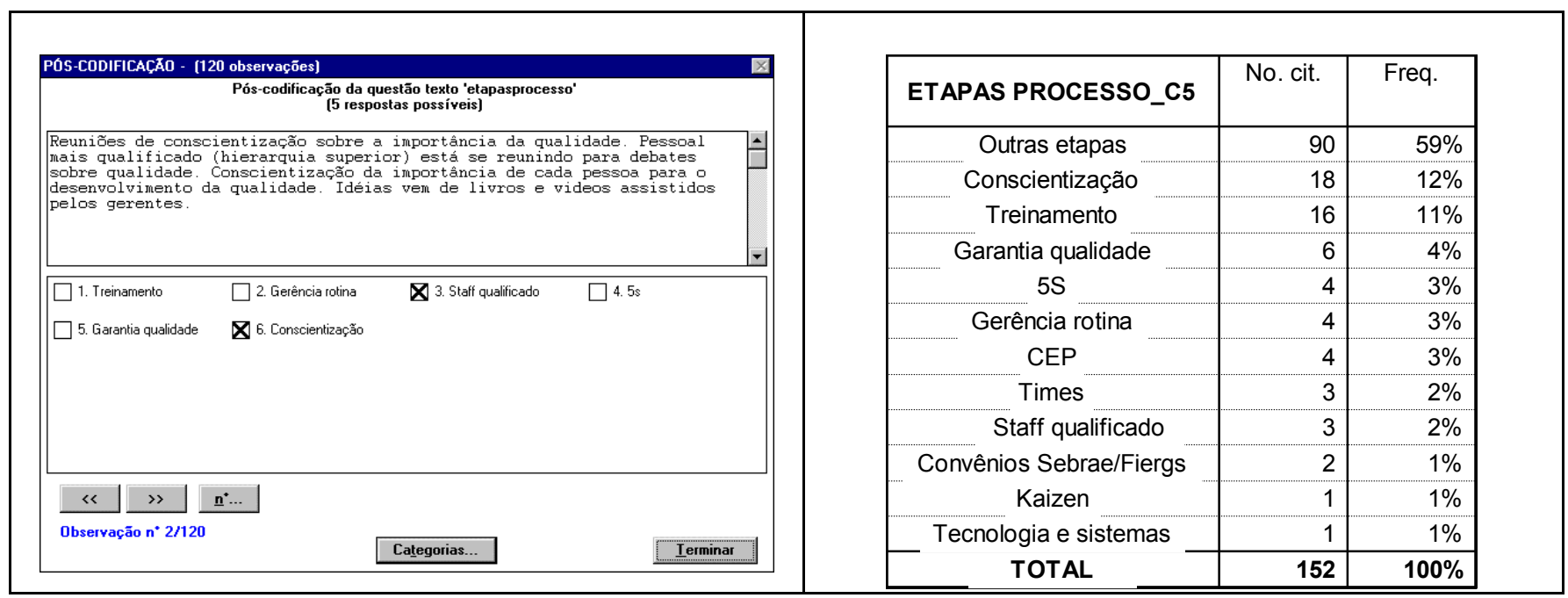

Figura 18 - A análise de conteúdo, com a codificação inicial (esq.) e o resultado derivado (dir.)

Este é um contexto no qual pode-se ler e anotar o conteúdo do que é lido, com a possibilidade de enriquecer os temas que se está interpretando. É como se fosse uma tentativa de "fechar" a questão aberta. Este método apresenta contudo um problema: representa um trabalho maçante e demorado. É também um método subjetivo, como a leitura pode sê-lo; é um método clássico de análise de conteúdo. Mas ao seu final, a codificação resultante é expressiva da realidade inerente àquela amostra.

$\mathrm{Na}$ seqüência, tem-se a utilização da análise lexical, que apresenta algumas vantagens. $\mathrm{O}$ software em questão fornece a análise do conjunto das palavras que compõem o corpo dos textos respondidos, permitindo diversos tipos de contabilização e de navegação pelas respostas. Pode-se rapidamente verificar que no total as 120 respostas representam 2.335 palavras, as quais se transformaram em 1849 após a exclusão de 496 palavras chamadas ferramentas (artigos, preposições, etc.), e vê-se ainda que, entre essas 1849 palavras restantes ${ }^{9}, 805$ são diferentes. TQC, programa, ISO, eis palavras que pertencem ao campo da qualidade e que se pode identificar. Aprende-se rapidamente que a questão da qualidade está relacionada com a consciência, com a formação, com as regras ISO, com o pessoal, controle, etc. É o que possibilitam a navegação e a análise lexical.

\footnotetext{
9 Palavras seriam consideradas como uma forma gráfica, uma seqüência de caracteres que não comporta separador.
} 
Fez-se, enfim, a chamada aproximação lexical, ou seja, retirou-se da lista ou "léxico" todas as palavras chamadas ferramentas, que não comunicam diretamente uma idéia ou conteúdo no sentido da análise realizada, chegando-se às palavras de conteúdo ou significado. Toma-se conhecimento do que a qualidade evoca nas pessoas: trabalho, por exemplo. A palavra trabalho é citada onze vezes. Mas em que contexto? Faz-se a chamada navegação lexical, que consiste em ir diretamente às respostas onde foi citada a palavra em questão; pode-se exportar estas respostas para um documento em editor de texto. Este arquivo é chamado verbatim, que significa citação. A navegação lexical irá permitir a restituição das respostas, organizando-as de acordo com seu conteúdo, possibilitando conhecer em que contexto e com que sentido foi empregada a

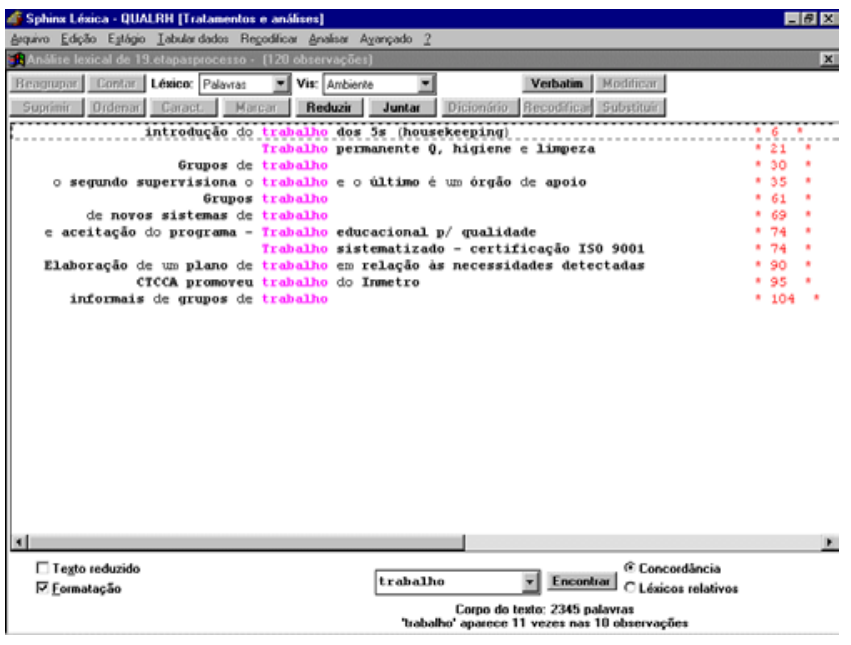

Figura 19 - O contexto da palavra "trabalho" palavra em questão.

Pode-se, a seguir, comparar as empresas em relação ao interesse dado à questão da qualidade, tomando-se a extensão da resposta como critério. Para isso, cria-se uma variável chamada tamanho, referente à quantidade de palavras contidas em cada resposta (visto na Figura 17). Compara-se, na seqüência, o tamanho de cada uma das respostas com o tamanho da empresa respondente. Conclui-se que existe uma relação expressiva entre o tamanho da empresa e a variável tamanho (Figuras 20 e 21): as empresas maiores se expressam de forma mais extensa a respeito de qualidade do que as empresas médias, e as pequenas pouco se expressam. Pode-se considerar que tem-se um indicador, grosseiro, do interesse das empresas por qualidade.

\begin{tabular}{|c|r|r|r|r|r|r|}
\hline $\begin{array}{c}\text { Tamanho } \\
\text { Porte }\end{array}$ & $\begin{array}{c}\text { Não } \\
\text { respostas }\end{array}$ & $\begin{array}{c}\text { Menos de } \\
17 \text { palavras }\end{array}$ & $\begin{array}{c}\text { De } 1731 \\
\text { palavras }\end{array}$ & $\begin{array}{c}\text { De 31 a 60 } \\
\text { palavras }\end{array}$ & $\begin{array}{c}\text { Mais de 60 } \\
\text { palavras }\end{array}$ & \multicolumn{1}{|c|}{ TOTAL } \\
\hline $\begin{array}{c}\text { Pequeno } \\
\text { Médio }\end{array}$ & 25 & 10 & 14 & 9 & 2 & $\mathbf{6 0}$ \\
\hline $\begin{array}{c}\text { Grande } \\
\text { TOTAL }\end{array}$ & 3 & 11 & 9 & 6 & 1 & $\mathbf{3 0}$ \\
\hline
\end{tabular}

Figura 20 - Cruzamento de porte da empresa $x$ quantidade de palavras no depoimento

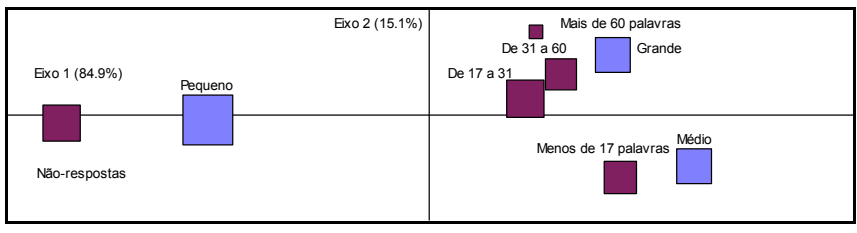

Figura 21 - O mapa AC do mesmo cruzamento

Pode-se ir além, marcando as palavras que dizem respeito à qualidade e analisando seu conteúdo. Tomam-se as palavras que reaparecem com mais freqüencia e cria-se uma variável fechada, que vai classificar cada empresa pelo uso de uma dessas palavras, recodificando a sua resposta. A seguir, cruzam-se as empresas respondentes (de diferentes portes) com as palavras mais citadas, com o objetivo de determinar se existem palavras características das grandes ou pequenas empresas. Desta vez, o interesse centra-se na diferença de significado do processo de qualidade, de acordo com o tamanho da empresa. É o que ilustram as Figuras 22 e 23 a seguir. 


\begin{tabular}{|c|c|c|c|c|}
\hline $\begin{array}{r}\text { Porte } \\
\text { etapas_10+ citadas }\end{array}$ & Pequeno & Médio & Grande & TOTAL \\
\hline Treinamento & 8 & 7 & 9 & 24 \\
\hline conscientização & 9 & $\overline{6}$ & 5 & 20 \\
\hline ISOO & 4 & $\overline{7}$ & 6 & 17 \\
\hline Grupos & 4 & $\overline{5}$ & 6 & 15 \\
\hline contrōele & 4 & $\overline{2}$ & 4 & ---- \\
\hline processo & 4 & $\overline{3}$ & 4 & ---- \\
\hline formação & 2 & $\overline{2}$ & 5 & --- \\
\hline TQ' $\bar{C}^{-1}$ & 0 & $\overline{2}$ & 5 & ----- \\
\hline Gerência & 3 & $\overline{3}$ & 4 & -10 \\
\hline cursos & 2 & $\overline{4}$ & 2 & 8 \\
\hline TOTAL & 40 & 41 & 50 & 131 \\
\hline
\end{tabular}

Figura 22 - Uma nova variável, fechada, sobre as 10

palavras mais citadas nas etapas, cruzada com o porte das empresas

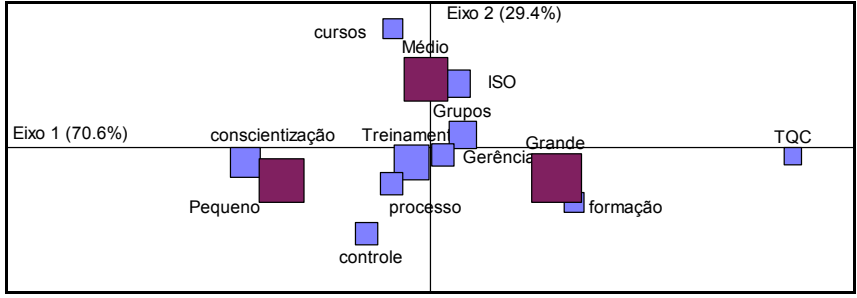

Figura 23 - O mapa AC do mesmo cruzamento

Analisando-se os dados um pouco mais (além do que as Figuras representam), podería-se notar que as pequenas empresas falam em: conscientização, controle, processo, enquanto que as médias e grandes empresas falam de: gerência, formação, ISO, grupos, um vocabulário mais técnico, mais especializado. Pode-se diagnosticar o fato de que o significado de qualidade é mais profundo para as médias e grandes empresas, mais do que para as pequenas. As grandes empresas assimilaram o vocabulário característico da abordagem da qualidade. As pequenas empresas são capazes de se expressar sobre qualidade, porém com um vocabulário mais comum, menos específico.

\section{2 - Da análise de conteúdo e da análise lexical à teoria dos atos de linguagem ${ }^{10}$}

Através de processos automáticos que associam a matemática e a estatística (vide caso anterior), o uso da análise lexical permite interpretar e fazer uma leitura adequada e dinâmica das questões abertas das enquêtes. Esse procedimento não é mais rigoroso do que a análise de conteúdo clássica. $\mathrm{O}$ tratamento dos dados é objetivo, mas a leitura subjetiva também é realizada; é ela que permite comunicar a impressão de acordo com a qual o processo de qualidade teve maior incorporação nas médias e grandes empresas do que nas pequenas. A subjetividade continua presente, mas através deste tratamento tem-se acesso a um processo de leitura mais rápido, automatizado e que, por outro lado, encontra um certo número de justificativas, que são abordadas na seqüência. Os dois tipos de análise de questões abertas (de conteúdo e lexical) são representados na Figura 24.

10 Estes tipos de análise de dados são abordados por KRIPPENDORFF (1980); WEBER (1990); GRAWITZ (1993); LEBART e SALEM (1994); MOSCAROLA (1993 e 1994); GAVART-PERRET e MOSCAROLA (1995); BARDIN (1996); FREITAS, CUNHA e MOSCAROLA (1996 c, 1997). 

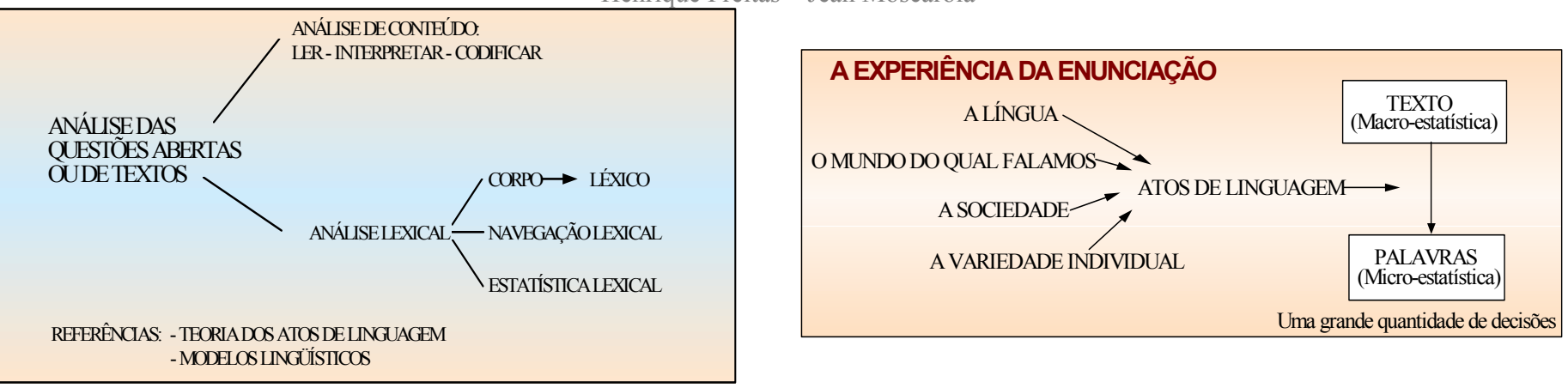

Figura 24 - A análise de conteúdo e a análise lexical Figura 25 - Análise lexical e os atos de linguagem

O método de análise apresentado consiste em partir de textos, respostas abertas, para analisar palavras, o léxico. Ao se fazer isso, parte-se de um nível que se pode chamar de macroestatístico: aquele das 120 entrevistas que foram realizadas, das 3000 ou 2000 palavras produzidas nas respostas. Estas palavras são resultados do que chamamos atos de linguagem. Os atos de linguagem são as decisões que tomamos ao nos expressarmos, ao escolher uma palavra em detrimento de outra (GRAWITZ, 1993).

Esses atos de linguagem dependem, por um lado, do idioma - este vem em primeiro lugar - mas dependem também do mundo do qual se fala e no qual se encontra a realidade. No exemplo acima citado, os atos de linguagem dependiam de todo um conjunto de conhecimentos a respeito de qualidade; a questão tratava de processos de qualidade. Os atos de linguagem expressam também o contexto social. No exemplo dessa enquête, esta é a idéia das grandes, pequenas e médias empresas. Enfim, os atos de linguagem dependem da variedade individual de quem está se expressando. Assim, a maneira como nos expressamos é certamente característica do Português. $\mathrm{Na}$ condição de pesquisadores, apresentamos um vocabulário certamente abstrato, com termos da estatística e com a particularidade de nosso estilo próprio como indivíduos. Tenta-se ilustrar todas essas questões na Figura 25.

Se for possível controlar o idioma e a variedade individual, pode-se, através da estatística dos atos de linguagem, descobrir ora o mundo do qual se está falando, ora o contexto social de quem estiver falando.

A análise lexical, ao apoiar-se na teoria dos atos de linguagem, oferece uma maneira científica de desenvolver investigações em áreas que tradicionalmente são objetos de uma única abordagem literária e subjetiva. A seguir, é examinado outro exemplo de pesquisa qualitativa que lança mão da Análise Lexical para tratamento dos dados.

\section{3 - A avaliação da comunicação interna de um grupo de empresas, utilizando-se a análise lexical}

Este caso trata de uma análise da comunicação interna em 10 empresas diferentes, pequenas empresas com 100 a 200 empregados, localizadas na França. Em cada empresa foram realizadas 10 entrevistas, perfazendo um total de 100 entrevistados. 


\begin{tabular}{|l|c|c|}
\hline \multicolumn{3}{|c|}{ FICHA TÉCNICA DA ENQUÊTE } \\
\hline INTERESSADOS & Diretoria de um grupo de pequenas empresas. \\
\hline OBJETIVOS & Realizar uma avaliação da comunicação interna realizada. \\
\hline \multirow{3}{*}{ AMOSTRA } & Tipo de público-alvo & Quantidade \\
\cline { 2 - 3 } & Funcionários das empresas & 100 pessoas \\
\hline
\end{tabular}

Figura 26 - A ficha técnica da enquête "comunicação interna"

Dessa pesquisa, são abordadas e analisadas duas perguntas abertas:

(1) De acordo com o senhor, o que não está satisfatório na comunicação interna da empresa? (Variável diagnóstico)

(2) Quais as sugestões que o senhor faria para melhorar essa comunicação interna? (Variável sugestão)

Busca-se na base de dados as duas variáveis em questão e calcula-se o número de palavras que compõem as respostas. Em média 38 palavras são utilizadas para formular o diagnóstico e 25 palavras para formular as sugestões. Isto denota que as pessoas em geral falam mais quando se trata de criticar do que quando se trata de propor, é um fenômeno até certo ponto comum. Definiu-se então um indicador de engajamento, que seria dado pela relação entre a intensidade (número de palavras) utilizada na formulação do diagnóstico, e a intensidade na formulação das sugestões de melhorias. Considera-se, pois, que as pessoas muito engajadas fazem sugestões intensas e são sucintas no diagnóstico. No caso estudado essa razão teve o valor médio 0,63 , o que já se esperava, pois foi colocado que as sugestões costumam ser mais concisas do que os diagnósticos.

Uma pergunta interessante feita aos respondentes é se eles consideram as informações das comunicações internas suficientes ou insuficientes. Analisando-se os dados coletados, verificou-se (Figura 27) que as pessoas que consideram as informações insuficientes são mais engajadas, ao mesmo tempo que boa parte (17 de 46) das pessoas satisfeitas com a informação que recebem são menos engajadas, algo que também se observa freqüentemente.

\begin{tabular}{|c|r|r|r|}
\hline $\begin{array}{c}\text { INFORMACAO COMPLETA } \\
\text { ENGAGAMENTO INDICAD }\end{array}$ & Suficiente & insuficiente & TOTAL \\
\hline Menor que 0.5 & & & \\
\hline De 0.5 a 1.0 & 17 & 15 & $\mathbf{3 2}$ \\
\hline Acima de 1.0 & 12 & 30 & $\mathbf{4 2}$ \\
\hline TOTAL & 17 & 7 & $\mathbf{2 4}$ \\
\hline
\end{tabular}

Figura 27 - Cruzamento de inf. sufic./insuficiente x engajamento

\begin{tabular}{|c|r|r|r}
\hline SEXO & Masculino & Feminino & TOTAL \\
ENGAGAMENTO INDICAD & & & \\
\hline Menos que 0.5 & {$[17$} & {$[15$} & $\mathbf{3 2}$ \\
\hdashline De $0 . \overline{5}$ a 1.0 & 26 & 16 & $\mathbf{4 2}$ \\
Acima de 1.0 & {$[20$} & 4 & $\mathbf{2 4}$ \\
\hline TOTAL & $\mathbf{6 3}$ & $\mathbf{3 5}$ & $\mathbf{9 8}$ \\
\hline
\end{tabular}

Figura 28 - Cruzamento de sexo $x$ engajamento

Considerando a variável sexo (Figura 28), verificou-se que os homens são mais engajados que as mulheres, as cores indicando as casas positiva e negativamente significativas (teste do Qui-quadrado). Estudando-se melhor os dados, constata-se que os homens tem um índice de engajamento de 0,82 e as mulheres de 0,56.

Estes resultados permitem pensar como se os homens, neste caso, fossem uma parte mais 'ativa' da população. Verificando-se o engajamento de acordo com a idade, os menores de 30 anos têm uma 
razão superior a um, ou seja, eles têm sugestões mais volumosas do que diagnósticos. Já os maiores de 50 anos são os menos engajados.

Do ponto de vista do cargo (Figura 29), nota-se que os mais engajados são os operários industriais ou de produção $(46 \%$ dos índices de engajamento acima de 1.0), a seguir os técnicos, e por fim os gerentes e os assalariados (pessoal administrativo ou funcional), nesta ordem.

\begin{tabular}{|r|r|c|c|c|c|}
\hline $\begin{array}{r}\text { CARGO } \\
\text { ENGAGAMENTO }\end{array}$ & assalariado & operário & técnico & gerente & TOTAL \\
\hline Menos que 0.5 & $34 \%(11)$ & $16 \%(5)$ & $25 \%(8)$ & $25 \%(8)$ & $\mathbf{1 0 0 \% ( 3 2 )}$ \\
\hdashline De 0.5 a 1.0 & $21 \%(9)$ & $26 \%(11)$ & $33 \%(14)$ & $19 \%(8)$ & $100 \%(\mathbf{4 2})$ \\
\hline Mais de 1.0 & $8 \%(2)$ & $46 \%(11)$ & $25 \%(6)$ & $21 \%(5)$ & $\mathbf{1 0 0 \% ( 2 4 )}$ \\
\hline TOTAL & $\mathbf{2 2} \%(\mathbf{2 2})$ & $\mathbf{2 9} \%(\mathbf{2 7})$ & $\mathbf{2 8} \%(\mathbf{2 8})$ & $\mathbf{2 2} \%(\mathbf{2 1})$ & $\mathbf{1 0 0 \% ( \mathbf { 9 8 } )}$ \\
\hline
\end{tabular}

Figura 29 - O engajamento e o cargo

A partir disso, pode-se chegar à conclusão de que, para promover a mudança na comunicação interna nas empresas estudadas, o mais acertado seria se apoiar sobre a população mais jovem, masculina e operária, de forma a se alcançar o resultado desejado. Essa interpretação, obviamente, pertence ao pesquisador. A análise lexical, contudo, fornece os meios para argumentar este ponto de vista à maneira dos científicos. Esses argumentos terão maior valor para as pessoas que acreditam que os números por si só são capazes de dizer a verdade. A análise realizada visa fornecer indicadores de ação e também justificativa para decisões tomadas, como forma de implementar ações previamente planejadas. Sem este fim, toda a análise não teria sentido.

\section{CONSIDERAÇÕES FINAIS}

Através dos métodos de pesquisa aqui apresentados, procurou-se demonstrar algumas maneiras de se realizar uma investigação de maneira prática e eficaz. As técnicas de análise de dados, ainda que tratadas sucintamente, mostram que é viável, com o auxílio de uma ferramenta estatística eficiente e de fácil manuseio, levantar e explorar informações consistentes que possam trazer respostas ágeis a muitos questionamentos que surgem no dia-a-dia de uma organização e mesmo no trabalho do profissional de pesquisa. Os preceitos a respeito das técnicas quantitativas e qualitativas procuraram levar o leitor a uma reflexão sobre o papel do pesquisador, as habilidades e concentração necessárias nesta verdadeira 'caçada' pelo conhecimento que se inicia ao se conceber e levar a termo uma investigação. Acredita-se que possa ser útil o debate da consciência necessária a respeito do que pode ser captado e de como se deve buscar as informações, especialmente para as pessoas que ainda não possuem grande familiaridade com essa atividade.

Através dos testes estatísticos (como, por exemplo, a Análise de Correspondência), pode-se oferecer suporte para a estruturação e exploração do conhecimento que pode emergir dos dados, e, além de tudo, para que se possa fornecer o embasamento para apresentação de idéias e descobertas a partir de uma investigação relativamente simples. Com exemplos práticos de enquêtes, pode-se constatar que a análise lexical pode ser útil para se tratar qualquer forma de texto, seja qual for a sua natureza, desde um discurso político até a documentação comercial, na publicidade, entre outros. Eis um último exemplo de como esse tipo de análise pode ser útil no mundo dos negócios: realizou-se uma investigação para um banco e analisou-se o conjunto dos documentos que o banco comunicava aos seus clientes. Fez-se a seguir uma entrevista com clientes do banco, onde falou-se de sua relação com o mesmo. Quando da análise das entrevistas, concluiu-se que o léxico utilizado nas comunicações do banco e o léxico utilizado por seus clientes em relação a ele não eram os mesmos: o banco falava do produto, enquanto que o cliente falava de seus problemas; o banco falava do quanto ele é bom e o cliente falava sobre as dificuldades nas quais se encontrava. Frente a isto, teve-se somente uma colocação a fazer ao banqueiro: procure falar a linguagem de seus clientes, dirija-se a eles. Diversos 
exemplos e abordagens de análise de dados podem ser encontrados em recentes livros de FREITAS e JANISSEK (2000) e de FREITAS e MOSCAROLA (2000).

Tal colocação diz respeito a uma coisa: bom senso, embora deva-se considerar que muitos de nossos interlocutores só se convençam pelo poder dos números. Daí a utilidade desse tipo de método para tratamento dos dados, de forma a comprovar, de maneira formal, evidências que muitas vezes são contundentes, mas nem sempre percebidas, e que, em boa parte das vezes, podem determinar o sucesso de um empreendimento. Os métodos e as ferramentas aqui apresentados deverão se tornar cada vez mais importantes frente ao manancial de informações com o qual nos confrontamos no nosso dia-a-dia. Tal qual o perfil dos investigadores que rememoramos (Poirot, Maigret, Holmes, ...), é fundamental apurar habilidades, tais como a capacitação não só para a manipulação das ferramentas que se possui, como o senso de direção para navegar através dos dados e (difícil tarefa) chegar a um porto seguro, ou pelo menos, à indicação de um caminho. Tal é a nossa esperança, de que esse trabalho possa ter fornecido noções interessantes sobre a atividade de pesquisa, especialmente àqueles que, cientes dessa realidade, pensam em se aventurar (e desfrutar) desse campo de inúmeras possibilidades.

\section{Artigo recebido em 08/04/2001. Aprovado em 07/11/2001.}

\section{REFERENCIAS}

BARDIN, L. L'analyse de contenu, 8. ed. Paris: PUF, 1996. 291p.

CALDIERARO, F.; FREITAS, H.; PETRINI, M. et al. Informação \& Modelos de Sistemas de Informação de Marketing. Proposto aos Cadernos de Estudo do PPGA, UFRGS, 1998 a, 15p.

CALDIERARO, F.; FREITAS, H.; PETRINI, M. e POZZEBON, M. Sistemas de informação de marketing: uma aplicação e seus resultados. Proposto aos Cadernos de Estudo do PPGA, UFRGS, 1998 b, 16p.

CARROL, J.D., GREEN, P.E. and SCHAFFER, C. Interpoint Distances Comparisons in Correspondence Analysis. Journal of Marketing Research, v. 23, Aug. 1986, p. 271-280

CARROL, J.D., GREEN, P.E. and SCHAFFER, C. Comparing Interpoint Distances Comparisons in Correspondence Analysis: a Clarification. Journal of Marketing Research, v. 24, Nov. 1987, p. 445450.

CUNHA Jr, M. Análise Multidimensional de Dados Categóricos: A Aplicação das Análises de Correspondência Simples e Múltipla em Marketing e Sua Integração com Técnicas de Análise de Dados Quantitativos. Porto Alegre-Brasil: Cadernos de Estudos do PPGA, UFRGS, 1998, 26p.

CUNHA Jr., M., FREITAS, H. e SLONGO, L. A. A pesquisa de marketing como fator de interação universidade-empresa: estudo de caso aplicado utilizando uma ferramenta (Sphinx ${ }^{\circledR}$ ) de estruturação e de análise quantitativa e qualitativa de dados. João Pessoa - PB: Anais do $19^{\circ}$ ENANPAD, ANPAD, v. 1, n. 05, Marketing, 25-27 Setembro de 1995, p. 109-129.

DAVIS, G. e OLSON, M. Management Information Systems. Mcgraw Hill, 1989

FOWLER Jr., F.J. Survey research methods. Sage Publ, Applied Social Research, v. 1, 1993. 156p. 
FRANKFORT-NACHMIAS, C. \& NACHMIAS, D. Research methods in the social sciences. St. Martin's Press, 1996. 600p.

FREITAS, H. e LESCA, H. Competitividade empresarial na era da informação. São Paulo/SP: Revista de Administração da USP, v. 27, n. 3, Julho/Setembro 1992. p.92-102.

FREITAS H. e JANISSEK R. Análise léxica e análise de conteúdo: técnicas complementares, seqüenciais e recorrentes para exploração de dados qualitativos. Porto Alegre/RS: Sphinx-Sagra (distrib.), (http://www.adm.ufrgs.br/professores/hfreitas/rev_hf), Julho 2000, 176 p.

FREITAS, H. e MOSCAROLA, J. Análise de dados quantitativos e qualitativos: casos aplicados usando o Sphinx ${ }^{\circledR}$. Porto Alegre/RS: Sphinx-Sagra (distrib.) (http://www.adm.ufrgs.br/ professores/hfreitas/rev_hf ), Julho 2000, 176 p.

FREITAS, H., BECKER, J. L., KLADIS, C. M. e HOPPEN, N. Informação e decisão: sistemas de apoio e seu impacto. Porto Alegre/RS: Ed. Ortiz, Setembro de 1997, 214 p.

FREITAS, H. A informação como ferramenta gerencial: um telessistema de informação em marketing para o apoio à decisão. Porto Alegre - RS: Ed. ORTIZ, Junho 1993. 360 p.

FREITAS, H., BALLAZ, B. e TRAHAND, J. Sistema de informações em marketing e apoio à decisão. São Paulo - SP: Revista de Administração da USP, v. 28, n. 2, Abril-Junho 1993, p. 33-49.

FREITAS, H., BRONGER, E. e CALDIERARO, F. SIM: sistemas de informações de marketing: desenvolvimento e operacionalização evolutivos. Anais do XVIII ENANPAD 94, ANPAD, Marketing, v. 7, Curitiba - PR, 26 a 28 de Setembro 1994, p. 260-276.

FREITAS, H. e BECKER, J. L. Uma agenda de pesquisas para a colaboração universidade-empresa em sistemas de informação e de decisão. São Paulo - SP: RAUSP, v. 30, n. 02, Abril-Junho 1995, p. 83-93.

FREITAS, H., BRONGER, E. e CALDIERARO, F. SIM: sistema de informações de marketing. Rio de Janeiro - RJ: Revista Decidir, ano II, n. 15, Outubro 1995, p. 22-29.

FREITAS, H., CUNHA Jr., M. e MOSCAROLA, J. Ferramentas gerenciais - Sphinx ${ }^{\circledR}$. Rio de Janeiro - RJ: Revista Decidir, ano III, n. 20, Março de 1996 a, p. 22-28.

FREITAS, H., CUNHA Jr., M. e MOSCAROLA, J. A Autonomia do Usuário pelo uso de um Sistema de Apoio à Pesquisa e à Decisão. Rio de Janeiro - RJ: Revista Decidir, ano III, n. 23, Junho de 1996 b, p. 32-39.

FREITAS, H., CUNHA Jr., M. e MOSCAROLA, J. Pelo resgate de alguns princípios da análise de conteúdo: aplicação prática qualitativa em marketing. Angra dos Reis - RJ: Anais do $20^{\circ} E N A N P A D$, ANPAD, Marketing, 23 - 25 de Setembro 1996 c, p. 467 - 487.

FREITAS, H., CUNHA Jr., M. e MOSCAROLA, J. Aplicação de sistema de software para auxílio na análise de conteúdo. SP: RAUSP, v. 32, n. 3, Julho-Set. 97, p.97-109 
GAVARD-PERRET, M.L. \& MOSCAROLA, J. De l'énoncé à l'énonciation: relecture de l'analyse lexicale en marketing. Annecy/France: GEREG and CERIAM, Université de Savoie, Cahier GEREG, $1995,34 p$.

GORETSKY, E. Frameworks of strategic marketing information needs. Industrial marketing management, v. 12, 1983, p.7-11

GRAWITZ, M. Méthodes des sciences sociales. 9.ed. Paris: Dalloz, 1993. 870p.

HOFFMAN, D.L. \& FRANKE, G.R. Correspondence Analysis: graphical representation of categorical data in marketing research. Journal of Marketing Research, v. 23, Aug. 1986, p. 213-227.

KOTLER, P. Administração de Marketing: análise, planejamento, implementação e controle. São Paulo: 2ed., Atlas, 1991, 848 p.

KRIPPENDORFF, K. Content analysis: an introduction to its methodology. The Sage CommText Series, 1980, 191p.

LEBART, L.; SALEM, A. Statistique Textuelle. Paris: Dunod, 1994. 342p.

LESCA, H., FREITAS, H. e CUNHA Jr., M. Instrumentalizando a Decisão Gerencial. Rio de Janeiro RJ: Revista Decidir, ano III, n. 25 Agosto 96, p. 6 a 14.

MATTAR, F.N. Pesquisa de Marketing. SP: Atlas, 1994

MISHLER, E.G. Research Interviewing: context and narrative, Harvard University Press, 1991.

MOSCAROLA, J. Enquêtes et analyse de données. Paris: Vuibert, Gestion, 1991

MOSCAROLA, J. Analyse de contenu et analyse de données: solutions logiciels pour une intégration quali/quanti. Paris: Actes JADT, 1993.

MOSCAROLA, J. Les actes de langage: protocoles d'enquêtes et analyse des données textuelles. Paris: Colloque Consensus Ex-Machina, La Sorbonne, April 1994.

PERRIEN, J., CHÉRON, E.J., e ZINS, M. Recherche en marketing: méthodes et décisions. Québec: Gaetan Morin ed., 1984

PORTER, M. E. Vantagem Competitiva. Rio de Janeiro: 6ed., Campus, 1992, 516p.

POZZEBON, M. e FREITAS, H. Construindo um E.I.S. (Enterprise Information System) da (e para a) empresa. São Paulo: RAUSP, v.31, n. 4, Out./Dez. 1996, p. 19-30.

RIBEIRO, Júlio. Fazer acontecer. SP Cultura editores associados, 1994

RUAS, R.L., PIRES, M., FREITAS, H., ANTUNES, E., CUNHA Jr, M. e equipe técnica. Pesquisa indicadores da qualidade e_produtividade. Pesquisa com 120 empresas gaúchas em parceria PPGA/UFRGS, IEL/FIERGS, SEBRAE, Relatório executivo, Porto Alegre - RS, Dezembro 1994, 
$68 \mathrm{p}$.

SCHEWE, C.D. e SMITH, R.M. Marketing: conceitos, casos e aplicações. São Paulo: MacGraw, 1980,564 pág.

SLONGO, Luiz A . Pesquisa de Marketing. Porto Alegre:Jornal Diário do Sul, 23/3/87, p.18

SPHINX LÉXICA for Windows (C), User's guide. Sphinx Brasil (e-mail: sphinx@portoweb.com.br website: http://www.sphinxbrasil.com), 2001.

WEBER, R.P. Basic content analysis. Sage university paper, 1990. 96 p. 